\title{
Where You Came From and Where You Are Going: The Role of Performance Trajectory in Promotion Decisions
}

AQ: au

\author{
Guido Alessandri \\ Sapienza University of Rome
}

Zitong Sheng

Virginia Commonwealth University and Curtin University

\author{
José M. Cortina \\ Virginia Commonwealth University \\ Laura Borgogni \\ Sapienza University of Rome
}

\begin{abstract}
Despite the clear theoretical link between promotions and job performance, the few studies that have tested this relationship have instead found that the role of job performance level in determining promotions is much less than might be expected. In 4 studies, we propose and test a different way of thinking about the performance-promotion relationship. Prospect theory, spiraling theory, and sponsored and contest mobility were used to support the notion that change in performance is at least as important to the prediction of promotion decisions as is absolute level of performance. In Study 1, performance and promotion data were collected for 563 white-collar employees at each of 4 time points spread over 6 years. As hypothesized, change in job performance significantly predicted change in workers' hierarchical level (i.e., promotion) beyond previous performance level. In Study 2, we found that upward trends are associated with ratings of future performance expectation and promotability through their effects on attributions of conscientiousness, proactive personality, and job dedication. In Study 3, we replicated the findings of Study 2 and found no evidence of a performance trend by performance level interaction. In Study 4, we showed that those with upward trends are preferred even to those with performance that is consistent and strong. Taken together, our results suggest that the reason for the modest performancepromotion relationships found in previous research may be that performance trends are seen by decision makers as containing at least as much promotion-relevant information as do performance averages or recent performance levels.
\end{abstract}

Keywords: job performance, latent growth model, performance change, promotions

Supplemental materials: http://dx.doi.org/10.1037/ap10000696.supp

It isn't where you came from, it's where you are going that counts. -Ella Fitzgerald

To be competitive, organizations need to attract and retain talented individuals (Breaugh, 2011; Sackett \& Lievens, 2008). One of the mechanisms through which high performers are incentivized to stay with an organization is promotion. Talented em-

Guido Alessandri, Department of Psychology, Sapienza University of Rome; (D) José M. Cortina, Department of Management and Entrepreneurship, Virginia Commonwealth University; Zitong Sheng, Department of Management and Entrepreneurship, Virginia Commwealth University, and Future of Work Institute, Curtin University; Laura Borgogni, Department AQ: 14 of Psychology, Sapienza University of Rome.

This research was supported in part by grants from Sapienza University of Rome (RG11816433CBD8D3 and RM11715C809391B1) to Guido Alessandri. Many thanks to Gilad Chen (who was not the action editor) for his feedback regarding mediators.

Correspondence concerning this article should be addressed to Guido Alessandri, Department of Psychology, Sapienza University of Rome, Via dei Marsi 78, 00185 Rome, Italy. E-mail: guido.alessandri@uniroma1.it ployees expect to get ahead quickly and to show a vertical career trajectory over time (Ng, Eby, Sorensen, \& Feldman, 2005). Given that positive supervisor evaluations of performance have been considered as necessary antecedents of promotability judgments (Wexley \& Klimoski, 1984), and given the tenets of the sponsoredmobility model of career success (Miller, Glick, \& Cardinal, 2005), it stands to reason that promotion would be strongly and positively related to performance ratings.

Despite the obvious theoretical link between promotions and job performance, the studies that have tested this relationship have instead found that the role of job performance in determining promotions is much less than might be expected. For example, Powell and Butterfield (1994) reported a correlation of .10 between promotion and a supervisor rating of performance. Lyness and Heilman (2006) found a slightly stronger relationship ( $r=$ .16), whereas Breaugh (2011) found a correlation just below zero $(r=-.04)$.

The staffing literature has long recognized the relevance of past behavior for the prediction of future behavior. For example, in spite of the expected simplex pattern, Henry and Hulin (1987) AQ: 5 found that the performance of major league baseball players (especially pitchers) in a given year predicted their performance even 
a decade later in spite of what must be a great deal of range restriction. Thus it seems perfectly reasonable that previous work on promotion has posited that job performance leading up to a promotion decision would be relevant for the suitability of an employee for a higher position in the organizational hierarchy. Therefore, the fact that previous research has found little to support this notion is surprising. This is especially so given the findings of Longenecker and Fink (2008), whose survey of managers suggested that past performance is accorded considerable importance in the promotion decision process, because it is seen as an indicator of ability and motivation. In short, the results from empirical studies of the performance-promotion relationship stand in vivid contrast to conventional wisdom and theory. This suggests that there is much more to be learned about the connection between performance and promotion.

The purpose of the present article is to develop and test a dynamic model of performance-promotion linkages. Specifically, we use prospect theory to argue that performance change would be salient to decision makers, spiraling theory to argue these trends would trigger stable attributions, and contest/sponsored mobility to explain what decision makers could be expected to do in response to these attributions. Our overarching hypothesis is that change in job performance is as important to decision makers as average or current performance when making promotion decisions. We then present four studies aimed at testing different aspects of our model.

In the first study, we test the relationship between performance change and promotion with a unique data set spanning four time points and 6 years. The data in Study 1 made it possible to examine the effects of performance change on hierarchical change within the organization (i.e., promotion). In Studies 2, 3, and 4, we explored the meaning that people attach to performance trends and that might influence promotion-related judgments. Specifically, we conducted controlled experiments aimed at testing the general hypotheses that (a) upward performance trends are associated with higher future performance expectations and perceived promotability through their effects on a variety of effort-related attributions such as job dedication and proactive personality, and (b) these attributions lead decision makers to favor those with upward trends over those with flat trends, even when their performance level is higher.

\section{Beyond Static Models of the Performance-Promotion Relationship}

As stated above, the idea that job performance drives promotion decisions is a basic one in management research. Managers seek to reward those who they perceive to have made the right choices in the past with promotion-related benefits. They also seek to provide additional responsibility to those whom they believe can cope with it. Providing promotion-related rewards to subordinates that impress them also cultivates perceptions regarding the value that is placed on performance. These tenets are consistent with a variety of theories related to human capital management including contest mobility and reciprocity norms (Blau, 1964).

Attempts to test hypotheses that flow from these frameworks have met with little success (see Breaugh, 2011 for similar points), generally yielding correlations between performance and promotion that are, at best, in the low teens. Although it is possible to attribute these findings to various design artifacts, these findings may be attributable to the fact that previous work has adopted a view of the performance-promotion process that is static rather than dynamic.

As Sturman (2007) pointed out, studies of job performance itself have tended to be cross sectional, suggesting that performance phenomena have been conceptualized as time-independent. An alternative conceptualization would impel one to consider the effect of performance trends on potential outcomes of performance. Given the suggested reasons for the dependency of promotions on job performance (Breaugh, 2011), as well as the nature of performance trajectories (Sturman, 2007), models of performance-promotion relationships that omit time are likely to miss aspects of performance that are salient to and relevant for those who must make promotion decisions. Static models assume that, insofar as promotion decisions are influenced by performance, they are influenced only by current (or perhaps average) level of performance. In other words, static models assume that, to return to the Ella Fitzgerald quote, it really isn't where you came from or, for that matter, where you seem to be going. It is only where you are that matters. As we explain in the next section, there is reason to believe that promotion decisions are also influenced by performance trends. Managers are presumably more likely to promote those performing at a high level than those performing at a low level, ceteris paribus. However, consider the case of two candidates with similar current levels of performance. Information regarding the paths that led to those levels might be considered useful in making promotion decisions. But does this information contribute to prediction beyond performance levels? We argue that the answer is yes. Put another way, we argue that decisions makers consider where you came from to predict where you are going (we discuss the wisdom of such consideration in a later section).

From a processual perspective, understanding the nature of the job performance- promotion relationship requires a theory of how these variables relate over time rather than simply how they relate (see Pitariu \& Ployhart, 2010). The reason is that managers may (for good or ill) use the trajectory of an individual's job performance to make predictions of his or her subsequent development, over and above his or her more recent levels (for similar arguments see Sturman \& Trevor, 2001). Most of the previous studies on this topic (e.g., Lyness \& Heilman, 2006; Powell \& Butterfield, 1994) have explained why job performance and hierarchical level should relate at a given point in time (i.e., a static hypothesis), and a couple of studies have examined whether job performance at time $t$ might relate to position in the organizational hierarchy at time $t+$ 1 (i.e., a lagged hypothesis, see Ployhart \& Vandenberg, 2010). In the present article, we explain how changes in performance should relate to changes in hierarchical level (i.e., a dynamic hypothesis). In other words, we examine the relationship between performance trajectories and promotion. In the sections that follow, we draw upon and extrapolate from prospect theory, spiraling theory, and sponsored/contest mobility theory to link performance trends to promotion decisions.

\section{Toward a Dynamic Model: The Effects of Performance Trajectory on Promotion}

Performance trajectory reflects systematic, directional changes in a person's mastery of activities and duties associated with a specific organizational role (Alvares \& Hulin, 1972; Sturman, 2007). Cognitive models of performance appraisal suggest that 
performance trends facilitate a rater's automatic categorization processes (DeNisi, Cafferty, \& Meglino, 1984). In other words, observations of certain performance patterns lead raters to search for and find explanations for the observed pattern, that is, attributions. These attributions then influence supervisor responses beyond the influence of job performance itself (Ashkanasy, 1989; Green \& Mitchell, 1979). Several studies have demonstrated that raters evaluate positive trends more favorably than negative trends (DeNisi \& Stevens, 1981; Lee \& Dalal, 2011; Reb \& Cropanzano, 2007). Increasing job performance trajectories suggest acquisition of knowledge and skills which, in turn, is driven by various factors. Of particular interest here are the relatively stable attributes that might be perceived by decision makers to be responsible for past knowledge and skill acquisition because they could be expected to lead to knowledge and skill acquisition in the future. These might be ability variables such as cognitive ability (Schmidt, 2002) as well as dispositional, motivation-related variables such as proactive personality and conscientiousness (Judge, Higgins, Thoresen, \& Barrick, 1999; Seibert, Crant, \& Kraimer, 1999). We discuss the specific attributes in detail in Study 2. For now, it is enough to say that upward trajectories signal to decision makers that the person in question possesses stable virtues that are relevant for their present job and possibly for a higher level job as well. On the other hand, flat or downward job performance trajectories suggest to decision makers a failure to acquire knowledge and skills, possibly due to a (perceived) lack of some of these stable attributes. Although stable performance trajectories could lead to positive attributions (Kelley, 1967), we argue that managers value attributes that imply a potential for future growth, and that upward trajectories imply such potential.

Consider the performance trajectories of the four employees in Figure 1. Traditional performance models would suggest simply that, if there were one promotion slot available, then employees A and B would have similar chances of being promoted, with employee A perhaps getting the nod because of higher mean performance. Employee A would also get the nod to the degree that first impressions drive the decision. In any case, employees $\mathrm{C}$ and D would have no chance.

As we explain below, there is reason to believe that employee B would be promoted ahead of employee A because of equal current performance but superior trajectory. But if trajectory really is important, and if the attributions to which they lead are fairly

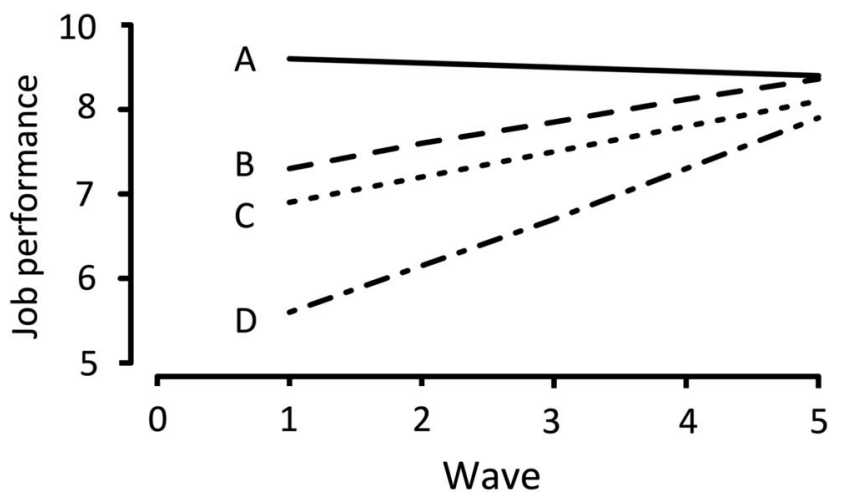

dramatic, then it might be that employee $\mathrm{C}$, whose current performance level is only slightly below that of employees A and B, might get the nod. It may even be that performance trends have such a powerful influence on attributions that employee D gets promoted in spite of a current performance level that is well below that of employees A and B.

It should be noted that promoting $\mathrm{D}$ or $\mathrm{C}$, or even $\mathrm{B}$ may not be the most rational decision. For example, although employee D may be the most conscientious and motivated of the group, employee D may also have had less job knowledge coming into the position and therefore had more ground the make-up. Our primary interest, however, is not in the future performance of those who are promoted but in the promotions themselves. In other words, our studies are intended to be descriptive rather than prescriptive. Traditional promotion models suggest that current or average performance suggests to decision makers attributes that will be useful at the next level. We argue that, just as managers ascribe certain attributes to subordinates based on performance level, so do they ascribe attributes based on performance trends. A promotion decision is essentially a type of forecasting decision, given that the decision maker has no direct information about the performance of the candidate in the job to which he or she might be promoted. Promotions require the capacity to grow into a role and master it, and managers are likely to attribute upward performance trends to a cluster of attributes that we might call the employee's capacity to improve, a capacity that should serve the employee well in a new role. Prospect theory and spiraling theory can be used to explain why decision makers might notice and ascribe certain virtues to those with upward performance trends, and contest/sponsored mobility can be used to predict what decision makers would do in response to these ascriptions.

\section{Prospect Theory}

Prospect theory (Kahneman \& Tversky, 1979, 1984) can be used to explain why decision makers would attend to performance trends in the first place. It suggests that decisions are influenced not only by perceived values of variables that are relevant for those decisions, but also by discrepancies between perceived values and reference points. Initial levels of variables, perhaps because of a primacy effect, serve as reference points, and departures from these initial levels are salient and are given meaning (Kahneman \& Tversky, 1984). In explanations of this notion, one often sees an example like the following. Suppose that Person A had five million dollars yesterday, but gambled and lost, and now has one million. Person B had one hundred thousand dollars yesterday, gambled and won, and now has one million. From a purely rational, von Neumann and Morgenstern (1944) perspective, these two people should be equally satisfied with their wealth. But because humans base judgments not only on the current state of affairs but also on a comparison of that state to the previous state (i.e., the reference point), Person B will be more satisfied with her wealth. ${ }^{1}$

For the present purposes, the initial level of performance of a given subordinate would serve as a reference point for the decision

\footnotetext{
${ }^{1}$ As this is being written, most of the world is in lockdown because of the COVID pandemic. The Dow has lost half of its value. Anyone whose retirement investments were mostly in stocks understands the salience of departures from reference points.
} 
maker. Given the power of first impressions (Thompson, 1998), initial performance would be salient to decision makers, leading them to attach particular importance to it. If there were no more to decision making, then those who perform well initially would be promoted, and those who start slowly wouldn't. But prospect theory suggests that although initial performance would matter, the trend leading away from this reference point, the so-called subjective value function (Kahneman \& Tversky, 1979), is also salient. Moreover, decision makers attempt to make sense of this function through attributions. Where the subjective value function is a performance function, attributions would be performance-related, and these attributions could then be expected to influence promotion decisions.

The role of departures from reference points has been examined in a variety of organizational science models. Hsee and Abelson (1991; see also Hsee, Abelson, \& Salovey, 1991) introduced the term "velocity" to indicate the slope of trends. ${ }^{2}$ Hsee and colleagues showed that satisfaction was determined not only by current state of, for example, salary (i.e., position) but also by velocity such that many respondents were more satisfied with higher velocity salary (i.e., a larger increase) than with higher position salary (i.e., a larger final value). Chen, Ployhart, Thomas, Anderson, and Bliese (2011) offered similar justifications in describing the relationship between job satisfaction change and turnover intentions. Chen et al. (2011) suggested that a given level of satisfaction might have different significance for two people who came to that level from different directions. Returning to the realm of performance trends, Harrison, Virick, and William (1996) used relative deprivation theory to argue that reactions to outcomes are determined not only by the level of those outcomes but also by comparison of those outcomes to their past levels. Sturman and Trevor (2001) took this notion one step further by arguing that performance trend (rather than merely a comparison of present to past) would contribute to the prediction of turnover.

The dependent variable in these studies was attitudes regarding oneself, but similar arguments can be made regarding attitudes toward others. A decision maker who is evaluating two promotion candidates who have, for example, similar current levels of performance is likely to consider how they arrived at those levels. Barnes, Reb, and Ang (2012) showed that organizations compensate employees with upward trends at a higher level than employees with downward trends even given the same mean level of performance. We delve into the specific attributions that decision makers are likely to make from different performance trends later in the article. For the time being, we suggest that prospect theory can be used to link performance trends of others to one's own evaluation of those others. Just as one's own departure from a prior reference point is salient to oneself, so is it salient to others. Just as the turnover intentions of Person A may be influenced by a downward performance trend (to paraphrase Sturman \& Trevor, 2001), so should attributions and decisions regarding Person A by Person B be influenced by that downward trend.

\section{Spiraling Theory}

With the salience of the reference point and the trends leading away from it established, spiraling theory (Lindsley, Brass, \& Thomas, 1995) helps to explain part of the job-relevant meaning that is attached to those trends. Spiraling theory suggests that velocity is related to perceptions of stability of patterns. The focus of Lindsley et al. (1995) was on self-perceptions and efficacyperformance spirals, and Chen et al. (2011) also drew upon spiraling to link satisfaction trend to turnover intentions. As was the case with prospect theory, the principles of spiraling theory apply just as well here. High velocity (e.g., substantial increases in performance) leads to perceptions (by the decision maker) that the forces that led to the velocity are there to stay. Noticeable upward departures from initial performance suggest to decision makers that the forces that led to those departures, whatever they might be, will still be there tomorrow. Downward velocity suggests an absence of these forces or perhaps the presence of undesirable forces.

Decision makers then use velocity-based attributions to make promotion decisions. Later in the paper, we argue that upward velocity is attributed by decision makers to stable characteristics such as conscientiousness. For now, we suggest that velocity prompts in decision makers attributions of relatively stable characteristics that they believe to be relevant and are likely to be present in the future. In other words, they engage in what Ariely and Carmon call "naïve extrapolation" (2003). As we explained earlier, this sort of extrapolation may or not be wise. That said, such attributions are not without basis given that, if one were to perform equally well in a "promoted" role as one did in a lower role, this would be a sort of upward trend, and the production of such a trend would presumably require the same attributes that would be required of performance improvement in a single role. In other words, just as upward velocity indicates stable attributes that allowed a candidate to improve in his or her current role, so should it indicate attributes that would allow one to grow into a new role. As a result, decision makers are more likely to promote the person with upward velocity.

\section{Sponsored and Contest Mobility}

Finally, if performance trends are in fact salient to decision makers, and if those trends suggest to decision makers certain virtues, then the notions of sponsored and contest mobility can be used to link those trends to promotion. Sponsored mobility suggests that decision makers pay special attention to individuals deemed to have high potential. Decision makers provide these "HiPos" with advantages that lead to advancement and success (Maurer \& Chapman, 2013). In building upon Turner's (1960) notion of sponsored mobility, $\mathrm{Ng}$ et al. (2005) suggested that shrewd managers make an attempt to invest in valued employees. Promotion is one of the most powerful forms of investment by the organization in the ascendant employee. The typical application of sponsored mobility to the performance-promotion relationship would involve the link between early performance and promotionrelated variables. As Ng et al. (2005) put it, "those who have early successes are more likely to receive sponsorship" (p.370). But if our earlier reasoning is correct, then decision makers would want to sponsor the upward mobility not just of those who began at a high level, but also those whose trajectories are in the right direction. The idea is that, in accordance with an implicit reciproc-

\footnotetext{
${ }^{2}$ The term velocity is a bit of a misnomer in that it refers to the magnitude of difference rather than the speed with which the difference was achieved.
} 
ity norm (Blau, 1964; Yukl, 1994), supervisors noticing an upward trend in the job performance of a certain worker may decide to promote the person, expecting the person to reciprocate by continuing the trend. Supervisors noticing a flat trend would see less reason to invest because there is no upward trend to continue. Research has suggested that people who seek to improve their performance are identified as HiPos (Lombardo \& Eichinger, 2000). Whether such people actually possess more potential is debatable. Our point is that an upward trend would lead to conferral of HiPo status by decision makers who would, in turn, provide opportunities for advancement.

Of course, if sponsored mobility can be extended in this way, then so can contest mobility. Contest mobility suggests that there is an open contest for each prestigious position. Individuals compete for these prestigious positions, and performance determines upward mobility (Turner, 1960). The traditional notion of the contest in contest mobility would focus on current, or perhaps average performance (Miller et al., 2005; Turner, 1960). If, however, one adopts a broader perspective, then one can see that decision makers might consider an upward trend to be part of the contest. This is not unreasonable if the prize for the winner of the contest is promotion, with the decision maker attributing an upward trend to attributes that will be useful for the new position.

Putting together the implications of prospect theory, spiraling, and mobility, we have the following. Initial performance serves as a reference point - a sort of anchor - and is therefore salient to the decision maker. If the reference point is salient, then so are departures from it. Spiraling theory suggests that decision makers imbue those whose performance is improving noticeably (i.e., those with upward velocity) with certain stable virtues and that these virtues are likely to be seen as useful in acquiring the knowledge and skills needed to perform a new role just as they were useful in acquiring what was needed to improve in the old role. Upward trends then lead to promotion because decision makers want to hold onto and cultivate the efforts of subordinates who possess the virtues that allow them to improve and to win. Thus, on the basis of prospect theory, spiraling, and sponsored/ contest mobility, we hypothesize the following dynamic hypothesis:

Hypothesis 1: Performance trend, that is, change in performance, contributes to the prediction of promotion, that is, change in hierarchical level, beyond performance level.

\section{Study 1}

Based on the above reasoning, we begin with a field study designed to investigate a general research question regarding the relative importance of performance level versus performance trend. Most studies of performance-promotion relationships seem to be based on an assumption that current performance is what matters to decision makers. Prospect theory, on the other hand, would suggest that departures from initial reference points would also be salient, and spiraling theory helps to flesh out this meaning. Sponsored and contest mobility then explain the behaviors that are triggered by this meaning. Study 1 is designed to pit this perspective against the traditional perspective. We note once again that our interest is not in what decision makers should do (i.e., prescription) but rather in what they are likely to do (i.e., description) given different performance trends. We return to this issue in the General Discussion section. Study 1, described below, tests our trend hypothesis. Studies 2, 3 and 4 then attempt to explain these findings through examination of transmitting mechanisms.

\section{Method}

Research context and job descriptions. Participants in this study were employed by one of the largest companies in Europe and held office positions in a variety of functional areas (e.g., accountancy and control, corporate affairs, internal auditing, and legal affairs). ${ }^{3}$ This organization was also uniquely suited to our Fn3 study because hierarchical levels are standardized across the organization. Workers involved in this study can occupy one of four hierarchical levels, with levels differing in degree of responsibility, decision autonomy, influence on others, and salary. These organizational cadres are divided into four hierarchical levels (thus the Italian term, quadri). These levels are labeled, in descending order, $\mathrm{AA}, \mathrm{A}, \mathrm{BB}$, and $\mathrm{B}$.

The highest levels are the AA and A cadres. At these levels, workers have the responsibility to manage other managers, particularly those at the B and BB levels, and manage strategic organizational structures, carry out highly specialized work, have responsibility for important organizational functions in the commercial sphere, or manage projects of strategic interest to the company. The latter group of activities includes consulting, planning strategic activities, carry out research on specific topic, and application of innovative methods in the organizational routine.

A senior manager AA has high autonomy, specialization, and direct responsibility for the achievement of the organizational goals regarding financial and human resources or sales that span wide geographical areas. They also help to develop organizational policies. A Junior manager A has less autonomy, specialization, and direct responsibility for the achievement of organizational goals regarding financial and human resources or sales than a Senior manager AA, and he or she is subordinate to a Senior manager AA. The Senior specialist BB level is more regimented. These employees perform specific technical and professional tasks and supervise specific work teams. Finally, a Junior specialist B has the least autonomy, performing technical, administrative, or commercial tasks and providing support to lower-level employees in their work. For all cadres regardless of organizational level, a reward salary is awarded each year, recognized on the basis of the objectives achieved. This remuneration is considered incentive, and its size is greater for those in the higher cadres (see the online supplemental materials for a full description of those roles).

Sample. The organization strongly encouraged its employees to participate in the project. This minimized the amount of missing data across the six years of data collection (see below). The four waves of data were collected in 2007, 2009, 2010, and 2013. A 6-year time window is rare for a study of this nature, but it was necessary for a sufficient amount of change in both performance and hierarchical level to occur. Four waves are also the minimum required for the examination of the effects of nonlinear performance trends on promotion (Sturman, 2007). Mitchell and James

\footnotetext{
${ }^{3}$ Study 1 was approved by the Sapienza Department of Psychology Institutional Review Board. Studies 2-4 were approved by the Institutional Review Board of Virginia Commonwealth University.
} 
(2001) called for more theory-based selection of time lags, and although it would be difficult to determine a precise optimal time lag for the study of the relationship between performance trend and promotion, the lag should be long enough for noticeable performance trends to emerge and for promotions from one hierarchical level to the next to have a chance to unfold.

In 2007, at the first wave of data collection, the sample size was 563 workers (of more than 1,300 contacted; response rate $=43 \%$ ). About $42 \%$ of participants at Wave 1 were male, and about $58 \%$ females. ${ }^{4}$ The mean age was $39.89(S D=9.40)$ years, with an average job tenure of $16.72(S D=10.10)$ years. Years of education ranged from 8 to $18 ; 56 \%$ of individuals had earned a university degree, $43 \%$ had completed high school, and $1 \%$ junior high school. These percentages were roughly consistent across waves.

Attrition. There were some missing data for some of the participants who began the study. Specifically, no participant was lost from Wave 1 to Wave 2 (in 2010). However, $10 \%$ (i.e., $N=$ $57)$ of the workers who participated in Wave 2 were absent from Wave 3 (2011), and an additional 27\% (i.e., $N=151$ ) missed data collection at Wave 4 (2013). Attrition was due in part to the fact that some participants retired. Another common reason for attrition was that some participants moved to other parts of the company, and performance data were no longer available to us. Given that the turnover rate was quite low during the time of the study (less than $1 \%$ according to organizational records), very little of the attrition would have been due to termination or to movement to a different company. The overall retention rate was $63 \%$, which is quite good for a six year, four-wave study (see Hansen, Tobler, \& Graham, 1990).

We conducted $t$ tests comparing dropouts to those who completed all four waves using wave 1 data. No significant differences were detected in major study variables and controls except for age and gender. The effect sizes were small (Cohen's $d$ s in the range of .03-.06) and were largely driven by the fact that some attrition was due to retirement, with retirees being older and more likely to be male. The groups did not differ in the covariance matrices as tested by the Box-M test. To further examine that the missing values were missing completely at random, we performed the MCAR test (Little \& Rubin, 1987). This test resulted in a nonsignificant value (i.e., $\chi^{2}=99.80, d f=80, p=.06$ ). Thus, we handled missing data in Mplus 8.30 by using the full information maximum likelihood (FIML) algorithm.

Procedure. Performance ratings and information regarding career advancement were provided at the end of each year by the Human Resources (HR) department by way of their performance appraisal system. In December of 2007, 2010, 2011, and 2013, every supervisor completed the performance appraisal form described below (referring to the period from January to December); between January and March the organization communicated this evaluation to the subordinates through a detailed feedback process. Then, between September and October of the same year, eventual hierarchical level advancement (promotions) were communicated to the interested workers. Although equal time spans between data collections would have been ideal, this was not possible. To account for differences in time span, slope factor loadings in latent AQ: 7 growth modeling (LGM) were fixed to 0, 3, 4, and 6 as recommended by Bollen and Curran (2006). Hierarchical level was the one registered for the year just finished; the same for which the job performance evaluations were made available.

\section{Measures.}

Job performance. Supervisors rated their employees' performance using an instrument developed by the human resource department of the organization as a general, unidimensional measure of task performance. Items addressed customer focus ("Anticipates client needs"), communication ("Adjusts his or her communication style to different people"), network management ("Builds up constructive relationships to achieve common results"), problem solving ("Identifies problems correctly and finds appropriate solutions"), and change management ("Explores new opportunities that contribute to the ongoing change process") on a 10-point scale (labels: 1 = inadequate; from 2 to $3=$ improvable; 4-6 = average; 7-9 = elevated $; 10=$ beyond expectations) Coefficient $\omega_{\mathrm{h}}$ (McDonald, 1999) and coefficient alpha for this 5-item scale were .91 and .92 at Wave 1, .93 and .92 at Wave 2, .94 and .95 at Wave 3, and .91 and .95 at Wave 4. The same performance appraisal system was used for all four of the hierarchical levels included in our sample, thus allowing performance comparisons across hierarchical levels.

Hierarchical level. The four hierarchical levels occupied by workers in this sample were coded from 1 (highest level, or level AA) to 4 (lower level or level B) and treated as ordinal because this organization considers these levels as an ordered sequence of low to high level managerial positions.

Control variables. We controlled for several potential confounding factors that have been found to relate to both promotion and performance. $\mathrm{Ng}$ and Feldman (2008) found a relationship between age and performance, whereas $\mathrm{Ng}$ et al. (2005) found a relationship between age and promotion. $\mathrm{Ng}$ and Feldman (2010) found a relationship between job tenure and performance, whereas $\mathrm{Ng}$ et al. (2005) found a relationship between tenure and promotion. As suggested by an anonymous reviewer, we also controlled for Educational level. Data for all three control variables came from company records. Tenure was operationalized as number of years or fractions of years at the organization at our first measurement period. Education was operationalized as years spend in the educational system, from grade school through any baccalaureate or graduate work. ${ }^{5}$

Modeling strategies.

Latent growth model. The latent growth curve (LGC) framework (Bollen \& Curran, 2006) was applied to test the hypotheses regarding longitudinal change in job performance and hierarchical level. For each construct, we tested a series of nested models. These models were compared with each other to determine the basic form of the growth trajectories for performance and for hierarchical level as suggested by Stoolmiller (1994). For each, two latent variables, the intercept and the slope, were specified from the four repeated measures of the constructs of interest.

\footnotetext{
${ }^{4}$ All participants were white Caucasian (this is still very common in this part of Europe).

${ }^{5}$ Note that race was essentially a constant (i.e., all participants were white Caucasian, an occurrence that is not uncommon in this part of Europe) and was therefore not included. Moreover, we had no information about marital status. However, although one can imagine marital status being related to promotion, it is difficult to see why its inclusion as a control would change the effects of performance trend.
} 
Importantly, in our study, the intercept was located at the initial measurement time (i.e., Wave 1 or year 2007), by fixing all the intercept factor loadings at one, and the first slope factor loading to 0 . Consequently, the means of intercept and slope are informative about the average trend and starting levels observed in our sample. The slope mean gives the growth rate of the variables over time, or more simply, the average change observed across waves. As such, it represents the average tendency uncovered in the sample. For example, a significant hierarchical level slope mean would imply an overall hierarchical level tendency to increase from Wave 1 to Wave 4, irrespectively (a) of the point where the much of the change happened and (b) of the point where a specific individual changed his or her hierarchical level. Importantly, the interpretation of this parameter depends on the specific change function that best fit the data. This require sequentially fitting different growth function and statistically compare them. To this aim, a sequence of three models was tested.

Model 1 assumes a significant sample level linear change across the four time points and systematic variability across individuals in intraindividual change (both the mean and variance of the slope were freely estimated). To accommodate the different spans between adjacent time points, the slope factor loadings were fixed to $0,3,4$, and 6, respectively. Model 2 assumes nonlinear growth for which the form of the change across time is not specified a priori. In this model, the first and the fourth slope factor loadings were fixed at 0 and 1 , whereas the second and the third factor loadings were freely estimated. The free loadings give flexibility in fitting nonlinear change and represent a kind of nonlinear spline that best fits the data between any two time-points. Under this model parametrization, the slope factor loadings value represents the proportion of change that occurred from the first time point up to a specific time point of interest (say, the change occurring between Wave 1 and Wave 3, e.g.) on the total amount of change observed across all time points (i.e., between Wave 1 and Wave 4). The slope value represents, instead, the average of the differences between last and first time point (i.e., between Wave 1 and Wave 4). Model 3 entails both a linear and a quadratic slope factor (by squaring the loadings used for the first linear slope), that together allow us to capture the curvilinear component of change observed in a construct over time. Finally, Model 2 and 3 further assume (as Model 1) a systematic variability across individuals in both the starting point (i.e., the intercept) and in intraindividual change (i.e., the slopes). Finally, in all models, the variances associated with the intercept and the slope reflect the degree to which these vary across individuals, and thus represent the random part of the model AQ: 8 (see Curran, 2003).

Multivariate latent growth model. After establishing the best univariate LGM for job performance and hierarchical level separately, we implemented a multivariate LGM model to examine relationships between change in performance and change in hierarchical level. This relationship is represented by the path predicting the hierarchical level slope by job performance change. Being this path significant, one would assume, for the average individual in this sample, the existence of a tendency for changes in hierarchical level to follow changes in job performance. In this model, the intercepts of job performance and hierarchical level were allowed to correlate, because they represent cross-sectional relationships among constructs. In addition, we regressed the slope of job performance on the intercept of hierarchical level, and the slope of hierarchical level on the intercept of job performance. We did this to adjust the prediction of change for the potential biasing effect of absolute mean level differences on each construct at Wave1 on the observed change (Cheong, MacKinnon, \& Khoo, 2003).

All analyses were carried out using the Mplus 8.30 statistical program (Muthén \& Muthén, 1998-2018). Whereas there has been considerable debate in the literature concerning the use of maximum likelihood estimation (ML) with ordinally scaled variables treated as continuous (West, Finch, \& Curran, 1995), different simulation studies have found ML performs well with variables with four or more categories (Bentler \& Chou, 1987) and under less-than-optimal analytical conditions (e.g., in the presence of small samples sizes and moderate departures from normality). However, because multivariate normality was untenable in the present sample multivariate skewness and kurtosis coefficients ranged from $120.77(p<.05)$ to $88.81(p<.05)$, we employed the Satorra and Bentler (2001) scaled chi-square statistic $\left(\mathrm{SB} \chi^{2}\right)$ and standard error, which takes into account the nonnormal distribution of the data (Mplus estimator = MLM: maximum likelihood estimation with Satorra-Bentler corrections). ${ }^{6}$

Because the chi-square is highly sensitive to the size of the sample, the $\mathrm{SB} \chi^{2}$ likelihood ratio statistic was supplemented with other indices of model fit, such as the comparative fit index (CFI) and the root mean square error of approximation (RMSEA) with associated $95 \%$ confidence interval. We considered CFI values greater than .95 and RMSEA values lower than .08 to be indicative of good fit (Kline, 2016). Because the difference between two scaled chi-squares for nested models is not distributed as a chisquare, the tenability of the constraints imposed for testing measurement invariance was examined with the scaled difference chi-square (Satorra \& Bentler, 2001). Given the sensitivity of the $\mathrm{SB} \Delta \chi^{2}$ test to sample size and error of specification, following Chen's (2007) recommendations we further evaluated the fit of the nested measurement invariance models according to the following criteria: $\Delta \mathrm{CFI} \leq .005$, and $\Delta \mathrm{RMSEA} \leq .01$. Instead, we assessed comparative fit of alternative growth functions last set of models with differences in Akaike information criteria (AIC; Burnham \& Anderson, 2004). AIC rewards goodness of fit and includes a penalty that is an increasing function of the number of parameters estimated. Better models are those with lower AIC values.

\section{Results}

Descriptive statistics. The descriptive statistics and correlations for the study variables are presented in Table 1. These T1 correlations were computed from the individual mean scores on the five items constituting the supervisor-rated job performance measure. As can be seen, there is a tendency for the cross-lagged correlation $\left(\bar{r}=.16, \bar{r}_{s d}=.06\right)$ between job performance and hierarchical level to be slightly higher than its cross-sectional counterpart $\left(\bar{r}=.13, \bar{r}_{s d}=.11\right)$. Indeed, the cross-sectional correlation between job performance and hierarchical level was not statistically different from zero at Wave 1 and Wave 2. Nevertheless, both cross sectional and cross lagged correlations were mod-

\footnotetext{
${ }^{6}$ As a sensitivity test, we also ran some of the models using the WLS estimator. The parameter estimates were nearly identical, and thus we present results obtained using the MLM estimator.
} 
Table 1

Descriptive Statistics

\begin{tabular}{|c|c|c|c|c|c|c|c|c|c|c|}
\hline Variable & 1 & 2 & 3 & 4 & 5 & 6 & 7 & 8 & $M$ & $S D$ \\
\hline 1. JP Wave 1 & 1 & & & & & & & & 7.69 & 1.37 \\
\hline 2. HL Wave 1 & .03 & 1 & & & & & & & 3.23 & 0.50 \\
\hline 3. JP Wave 2 & $.68^{* * *}$ & -.01 & 1 & & & & & & 8.06 & 1.32 \\
\hline 4. HL Wave 2 & .12 & $.77^{* * *}$ & .04 & 1 & & & & & 3.70 & 0.53 \\
\hline 5. JP Wave 3 & $.51^{* *}$ & .09 & $.52^{* * *}$ & .14 & 1 & & & & 7.80 & 1.17 \\
\hline 6. HL Wave 3 & $.19^{* * *}$ & $.74^{* * *}$ & .10 & .81 & $.23^{* * *}$ & 1 & & & 3.78 & 0.49 \\
\hline 7. JP Wave 4 & $.37^{* * *}$ & .09 & $.31^{* * *}$ & .17 & $.55^{* * *}$ & $.25^{\text {*** }}$ & 1 & & 7.87 & 1.12 \\
\hline 8. HL Wave 4 & $.22^{* *}$ & $.72^{* *}$ & .11 & $.84^{* *}$ & $.24^{* * *}$ & $.87^{* * *}$ & $.26^{* * *}$ & 1 & 3.62 & 0.49 \\
\hline 9. Gender & -.05 & -.03 & -.05 & -.01 & -.11 & -.00 & -.10 & .02 & - & - \\
\hline 10. Age & .08 & .02 & .03 & -.03 & .08 & .00 & .02 & -.04 & 39.89 & 9.40 \\
\hline 11. Job tenure & $-.24^{* *}$ & .07 & $-.29^{* * *}$ & -.15 & $-.25^{* * *}$ & -.12 & $-.37^{* * *}$ & -.04 & 16.72 & 10.10 \\
\hline
\end{tabular}

Note. $\mathrm{JP}=$ job performance; $\mathrm{HL}=$ hierarchical level.

*** $p<.01$.

est, which is consistent with prior research. Over time, we observed substantial rank-order stability for job performance $(\bar{r}=$ $\left..58 ; \bar{r}_{s d}=.08\right)$, suggesting that performance at time t was fairly strongly related to performance at time $t+1$. The autoregressive effect for hierarchical level was even stronger $\left(\bar{r}=.85, \bar{r}_{s d}=.10\right)$, although this is not surprising given the fact that hierarchical level at time $t+1$ was constrained by hierarchical level at time $t$ (i.e., two grade promotions are rare).

Longitudinal invariance. The configural invariance model included four correlated latent job performance factors (one for each time point), on which five items loaded. This model also included the covariances between the pairs of uniquenesses across waves, in accordance with recommended practices (Kline, 2016). This model fit the data well (Model 1, Table 2). We then proceeded with the metric invariance model in which we fixed all loadings to be invariant across time, and with the scalar invariance model in which item intercepts were constrained to be equal across time. As shown in Table 2, the data suggest high levels of invariance over time. Loadings ranged from .69 (Item 4, Wave 1) to .92 (Item 5, Wave 4), with a mean of $.84(S D=.06)$. We were therefore able to proceed with our growth models.

\section{Univariate latent growth models.}

Job performance. The LGM model for job performance was implemented on the scalar invariance model described above. Compared with all other models considered, the nonlinear growth model best fitted the data for job performance (see Table 3). Under this model, the estimates of intercept mean $(7.381, S E=.042)$ and variance $(.485, S E=.043)$, were significant (all $p<.05$ ). Likewise, the estimates of slope mean $(.404, S E=.056)$ and variance $(.228, S E=.048)$ were significant (all $p<.05)$. The significance of the slope mean indicates change in job performance across the six years of study. More change occurred between waves 1 and 2 than in later waves, thus producing the nonlinearity mentioned above. Indeed, the second (free) loading was significant $(p<.001)$ and equal to $.70(S E=.07)$. The third $(.001, S E=.041)$ and the fourth $(.04, S E=.056)$ loadings were not significant $(p=.91)$. Significant variances revealed individual differences in both intercept and slope for the latent trajectories in the construct. Job performance intercept and slope were not significantly correlated ( $p=.79$ ), suggesting that growth was independent of starting point. Estimated mean individual trajectory is presented in Figure 2A.

Hierarchical level. For hierarchical level, the LGM was constructed using observed scores. Overall, the fit of the quadratic and of the growth models were nearly identical, whereas both models fitted considerably better than the linear model (see Table 3). Thus, we focus on the more parsimonious nonlinear growth model. Under this model, the estimates of intercept mean $(3.43, S E=.02)$ and variance $(.218, S E=.010)$ were significant (all $p<.05)$. Likewise, the estimates for the slope mean $(.060, S E=.006)$ and variance $(.012, S E=.002)$ were significant (all $p<.05)$. The intercept represents the average hierarchical level observed at Wave 1 among the workers included in our sample. The significance of the slope mean indicates a change in hierarchical level

Table 2

Results From Confirmatory Factor Analysis and Measurement Invariance Analysis

\begin{tabular}{|c|c|c|c|c|c|c|c|}
\hline Model & $\mathrm{SB} \chi^{2}$ & $d f$ & CFI & TLI & RMSEA & {$[90 \% \mathrm{CI}]$} & AIC \\
\hline Model 1. Configural invariance & 527.93 & 134 & 0.940 & 0.920 & 0.068 & {$[.063, .080]$} & 23575.83 \\
\hline Model 2. Metric invariance & 543.27 & 146 & 0.939 & 0.930 & 0.068 & {$[.061, .070]$} & 23570.13 \\
\hline \multirow[t]{2}{*}{ Model 3. Scalar invariance } & 628.00 & 158 & 0.937 & 0.928 & 0.067 & {$[.064, .080]$} & 23633.83 \\
\hline & $\mathrm{SB} \Delta \chi^{2}$ & $\Delta d f$ & $p$ & $\Delta$ CFI & $\triangle$ RMSEA & & \\
\hline Metric vs. Configural & 16.28 & 12 & .179 & -.001 & -.000 & & \\
\hline Scalar vs. Metric & 78.12 & 12 & $<.001$ & -.003 & -.001 & & \\
\hline
\end{tabular}

Note. $\quad$ AIC $=$ Akaike information criteria $\mathrm{CFI}=$ comparative fit index $; \mathrm{CI}=$ confidence interval; $d f=$ degrees of freedom; $\mathrm{RMSEA}=$ root mean square error of approximation; $\mathrm{SB} \chi^{2}=$ values of the Satorra-Bentler scaled chi-square statistic; TLI $=$ Tucker-Lewis index. 
JOB PERFORMANCE AND PROMOTION

Table 3

Results From Latent Growth Modeling

\begin{tabular}{|c|c|c|c|c|c|c|c|c|c|c|c|c|c|c|}
\hline Model & $\mathrm{SB} \chi^{2}$ & $d f$ & $\mathrm{scr}$ & $p$ & CFI & RMSEA & {$[90 \% \mathrm{CI}]$} & AIC & Comparison & $\Delta \mathrm{SB} \chi^{2}$ & $\Delta \mathrm{scr}$ & $\Delta d f$ & $p$ & $\Delta \mathrm{AIC}$ \\
\hline \multicolumn{15}{|l|}{ Hierarchical level } \\
\hline M1. Linear model & 24.94 & 5 & 2.61 & $<.01$ & .909 & 0.080 & {$[.051, .113]$} & 1167.78 & M2 vs. M1 & 19.51 & 3.13 & 4 & $<.01$ & M2 \\
\hline M2. Quadratic model ${ }^{\mathrm{a}}$ & 7.72 & 1 & .51 & $<.01$ & 00.971 & 0.102 & {$[.044, .182]$} & 1114.65 & M3 & 9.92 & 6.12 & 2 & $<.01$ & M3 \\
\hline M3. Latent mo & 16.15 & 3 & .27 & $<.01$ & 0.940 & 0.081 & {$[.052, .130]$} & 1111.06 & M3 vs. M2 & 2.77 & .15 & 2 & .25 & M3 \\
\hline \multicolumn{15}{|l|}{ Job performance } \\
\hline M1. Linear model & 71.07 & 163 & 1.09 & $<.01$ & 0.910 & 0.081 & {$[.07]$} & 2378 & $\mathrm{M} 2$ & 37.02 & 1.49 & 4 & $<.01$ & M2 \\
\hline M2. Quadratic model ${ }^{\mathrm{b}}$ & 751.54 & 159 & 1.08 & $<.01$ & 0.914 & 0.078 & {$[.072, .083]$} & 23764.08 & M1 V & 131.53 & 1.09 & 2 & $<.01$ & M3 \\
\hline M3. Latent model & 639.54 & 161 & 1.09 & $<.01$ & 0.932 & 0.074 & {$[.063, .072]$} & 23642.43 & M3 vs. M2 & 61.35 & 1.89 & 2 & $<.01$ & M3 \\
\hline
\end{tabular}

Note. $\quad$ AIC $=$ Akaike information criteria; $\mathrm{CFI}=$ comparative fit index; $90 \% \mathrm{CI}=90 \%$ confidence interval associated with $\mathrm{RMSEA} ; d f=$ degrees of freedom; $p=$ significance of the $\Delta \mathrm{SB} \chi^{2} ; \mathrm{RMSEA}=$ root mean square error of approximation; $\mathrm{SB} \chi^{2}=$ values of the Satorra-Bentler scaled chi-square statistic; $\mathrm{scr}=$ scaling correction factor; TLI $=$ Tucker-Lewis index; $\Delta \mathrm{AIC}=\mathrm{AIC}$ preferred model; $\Delta d f=$ difference in $d f ; \Delta \mathrm{SB} \chi^{2}=\operatorname{corrected}$ differences in SB chi-square; $\Delta \mathrm{scr}=\operatorname{src}$ for $\Delta \mathrm{SB} \chi^{2}$.

${ }^{a}$ This model was not empirically identified with negative variance estimates for hierarchical level at T1 and T4. ${ }^{\mathrm{b}}$ This model was not empirically identified with negative variance estimates for the linear slope factor, and latent job performance at $\mathrm{T} 1$.

across the six years of study, with more change occurring between Waves 2 and 3. The estimated average individual trajectory is presented in Figure 2B. Significant variances revealed individual differences in both the intercept and slope for the latent trajectories in the construct. Estimated loadings were all significant $(p<.001)$ with values of $.29(S E=.063)$ at Wave 2, .61 $(S E=.058)$ at Wave 3 , and $.65(S E=.049)$ at Wave 4 . The expected negative covariance between the intercept and slope $(-0.28, S E=.055)$ indicates that workers who were higher in hierarchical level at Wave 1 changed their hierarchical level at a lesser rate than those who were lower at Wave 1.

Multivariate growth model. Finally, having established the presence of significant change and variability in job performance and hierarchical level, we tested our change hypothesis by building a multivariate latent growth model. This model was built on the previous two best fitting univariate latent growth models (LGM) for job performance and hierarchical level. To control for the potential confounding effects of workers' age and job tenure, we introduced these variables as covariates.

Specifically, additional paths were specified linking all covariates to the job performance and hierarchical level intercepts and slopes. The posited model fit the data well: $\mathrm{SB}^{2}(280, N=563)=$ 818.04, $p<.0001, \mathrm{CFI}=0.931$, TLI $=.919$, $\mathrm{RMSEA}=0.055$ $(0.051,0.061)$ and is represented graphically in Figure 3. Under this model, both job performance and hierarchical level had significant intercepts with significant variances, suggesting between individual differences in average levels of job performance and hierarchical level at the beginning of the study. The means of their slopes were not significantly different from zero, although their variances were, suggesting individual differences in slopes on both variables.

The intercepts of job performance and hierarchical level were not significantly correlated, meaning no relation between the hierarchical position at Wave 1 and the level of job performance at Wave 1, which is consistent with cross-sectional studies of performance-promotion relationships. Also, hierarchical level slope was significantly predicted by its intercept, suggesting that the hierarchical level of an individual at the beginning of the study naturally sets a bound on prospective change. As was the case with the univariate models, the intercept-slope relationship was weaker for performance than for hierarchical level and was in fact nonsignificant.

Now we turn to the analyses that are of most direct relevance to our model. As shown in Figure 3, the intercept of job performance significantly predicted the slope of hierarchical level. This is consistent with prior theorizing about performance-promotion relationships and suggests that the higher the job performance evaluation obtained by a worker at the beginning of the study, the higher the observed change in his or her hierarchical level over the course of the study. In other words, higher initial performers were more likely to be promoted (i.e., changing from one level to another) than were lower initial performers. Of most importance for our purposes is the relationship between job performance slope and hierarchical level slope. As shown in Figure 3, the slope of hierarchical level was significantly predicted by the slope of job performance, supporting H1. Because the weight for performance slope is a partial coefficient, it suggests that change in performance predicts change in level beyond either of the intercepts. In other words, change in performance predicted change in hierarchical level beyond initial levels of either.

To make the connection between analyses and hypotheses clearer, we ran another model in which the job performance intercept was performance at Wave 4 rather than Wave $1 .^{7}$ This Fn7 was accomplished by setting the first and fourth slope factor loadings to 1 and 0 while the second and third factor loadings were freely estimated. We did the same thing for the hierarchical level intercept using the same strategy. In all other ways, the model was identical to our original model. The results of this model were nearly identical to those of the original model (see Appendix 3, Model 3 in the online supplemental materials). Indeed, the weights for (a) performance trend in the prediction of hierarchical level intercept (i.e., hierarchical level at the last time point; .18, $\mathrm{z}=$ 2.97, $p<.01)$ and for (b) job performance level (.17, $\mathrm{z}=2.71$, $p \leq .01$ ) were both significant. Likewise, both the job performance

\footnotetext{
${ }^{7}$ To explore the correspondence between the latent slope at Wave 4 and the observed job performance score, we estimated the individuals' factor score on the intercept from the above model. Then we correlated it with job performance score at Wave 4 . The resulting correlation (uncorrected) was .92 .
} 

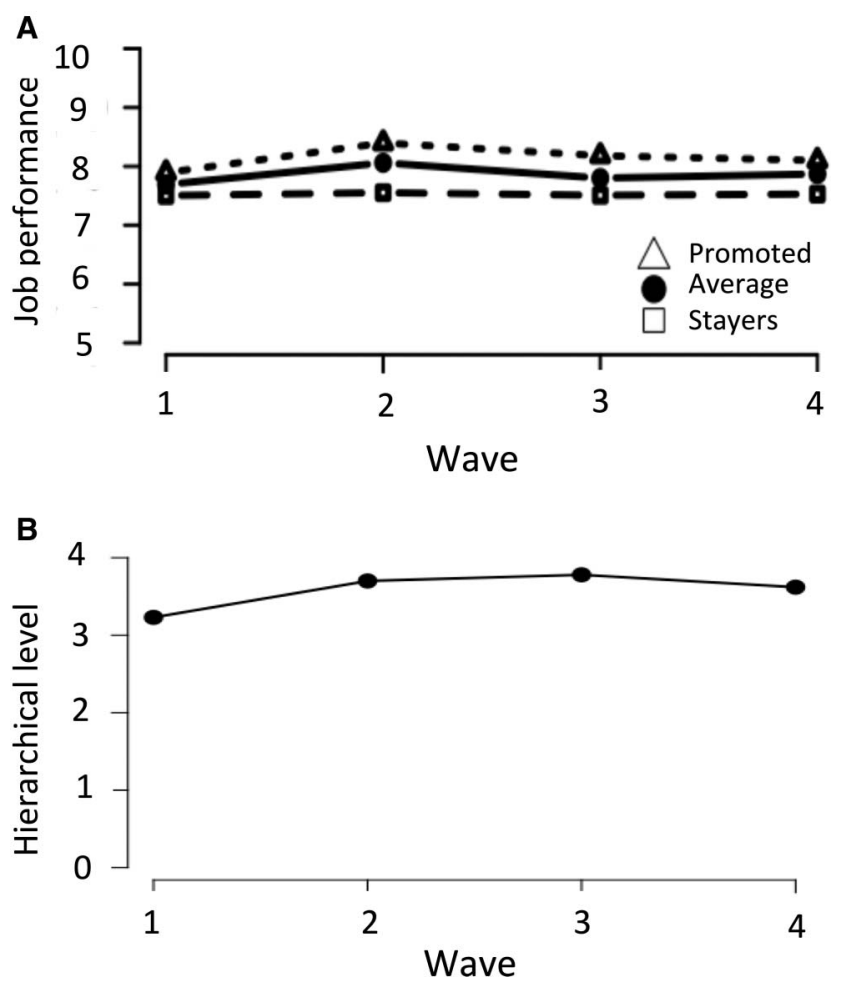

Q: 29 Figure 2. Longitudinal trajectories of (A) job performance and (B) hierarchical level.

intercept $(.19, \mathrm{z}=2.77, p<.01)$ and slope $(.12, \mathrm{z}=2.44, p<.05)$ significantly predicted hierarchical level trend. The magnitudes and the significance of the coefficients related to the prediction of hierarchical level slope by job performance trend in both models suggest that decision makers attach almost as much importance to performance trajectory as to performance level. Simply put, those with steeper, positive performance slopes were significantly more likely to be promoted than were those with flatter or negative slopes irrespective of performance at Wave 1 .

Moderation by initial performance level. We also explored the possibility of an interaction between performance and trajectory as it is possible that the perceived virtues of an upward trend might differ depending on early job performance. To this end, we tested two latent moderated structural equation models (LMS: Klein \& Moosbrugger, 2000). In Mplus 8.30 these models are estimated using a maximumlikelihood estimator with robust standard errors and a numerical integration algorithm (Muthén \& Muthén, 2018). The first is almost identical to the hypothesized model, except for the introduction of a new term representing the interaction between the job performance initial level (intercept) and trend (i.e., slope). This model, as with our original models, supported performance trend as a predictor of hierarchical level trend (see Appendix 3, Model 1a in the online supplemental materials). The interaction term, however, was not statistically significant (i.e., $.074, \mathrm{z}=1.34, p=.18$ ). Our second LMS (see Appendix 3, Model 2a in the online supplemental materials) was identical to the first except that the interaction between most recent job performance (i.e., job performance at Wave 4) and trend (i.e., slope) was used to predict hierarchical level at wave 4 . Thus we sought to examine whether prior performance moderated the relation- ship between performance trend and final hierarchical level. As with the first LMS, the interaction term failed to reach statistical significance (i.e., .09, $\mathrm{z}=1.44, p=.25$ ). Thus it seems that an upward trend is seen as a virtue irrespective of performance level.

Assuming a longitudinal perspective. Following a suggestion by an anonymous reviewer, we reparameterized the above model to examine whether job performance trend predicts change in hierarchical level controlling for most recent performance (rather than controlling for initial performance). To this aim, the value of the first and the fourth slope factor loadings were fixed respectively at 1 and 0 . In this way, the intercepts represent the worker's average job performance and his or her hierarchical level at Wave 4. Reliably detecting a nonlinear trend usually requires at least 4 time points (see Bollen \& Curran, 2006; Sturman, 2007). Using fewer than four time points can lead to important information loss, and consequently to unreliable parameter estimates (Muthén \& Curran, 1997; Sturman, 2007). Thus, we estimated job performance trend using all four waves of data, and focused on the prediction of hierarchical level at Wave 4.

As in the previous model, we predicted hierarchical level trend from (a) hierarchical level at Wave 4, (b) job performance at Wave 4, (c) performance trend, and (d) all covariates. Furthermore, in this model hierarchical level at Wave 4 was predicted by (a) the job performance at Wave 4, (b) job performance trend, and (c) all covariates. Results were consistent with our original analyses. First, there was a significant weight for job performance trend (leading up to Wave 4) in the prediction of hierarchical level intercept (i.e., hierarchical level at Wave 4; .19, $\mathrm{z}=2.72, p<.01$ ). Second, there was a significant weight for job performance intercept (i.e., job performance at Wave 4 in the prediction of hierarchical level intercept i.e., hierarchical level at Wave $4 ; .22, \mathrm{z}=$ $3.92, p<.01)$. Among covariates, only job tenure significantly and negatively predicted hierarchical level intercept $(-20, \mathrm{z}=3.89$, $p<.001)$. All in all, these analyses further attest to the importance of performance trend. The reparametrized model shows that performance trend leading up to Wave 4 contributes to the prediction of (a) hierarchical level change and (b) level at Wave 4 beyond, among other things, most recent performance level.

Ancillary analysis. Lyness and Heilman (2006) found that performance-promotion relationships were stronger for women than for men. This pattern was largely attributable to the fact that lowperforming men were sometimes promoted, whereas low-performing women were not. It may be that a similar form of bias exists in performance trend-promotion relationships. Just as men with low performance levels are sometimes promoted, it may be that men with flat or even negative trajectories are sometimes promoted. Women, on the other hand, may need to have positive trajectories to be promoted. Then again, it is possible that trend effects are more subtle and therefore less susceptible to gender bias than are level effects. We explored the potential moderating effects of gender using multiple group, multivariate LGM. We started by specifying the final multivariate LGM in the male and female groups simultaneously. This model, essentially a configural invariance model between sexes, fitted the data reasonably well: $\mathrm{SB} \chi^{2}(560, N=563)=1166.10, p<.0001$, $\mathrm{CFI}=0.936$, TLI $=.926, \mathrm{RMSEA}=0.061(0.057,0.067) . \mathrm{We}$ compared this model with the fit of a gender invariance model. In this model, we constrained the loadings and intercepts to be equal between groups (letting them be invariant over time, as before), as well as the intercept and slope means and variances, the covariance between the 


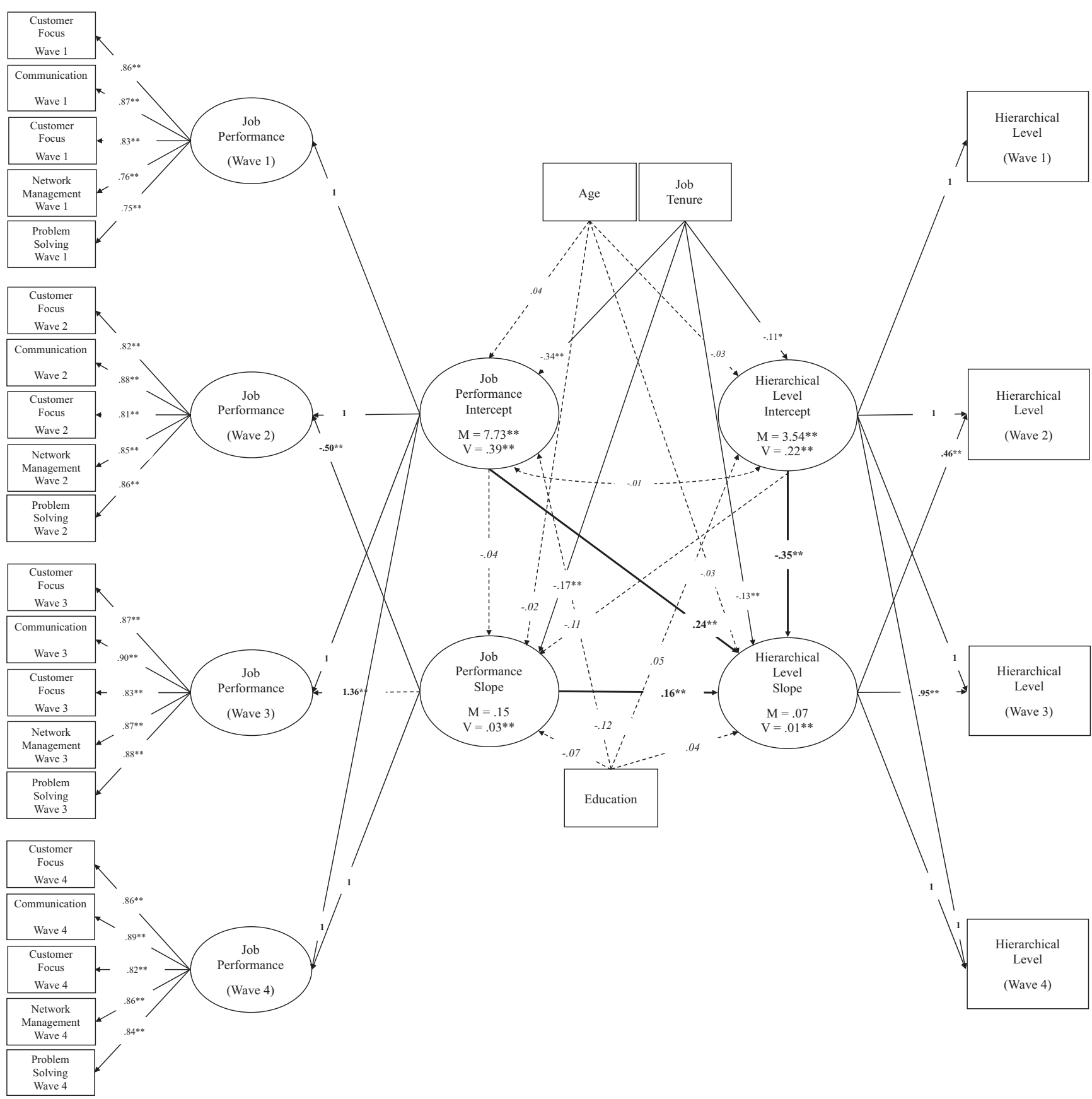

Figure 3. The multivariate latent growth modeling (LGM) model with parameter estimates. $M=$ mean; $\mathrm{V}=$ variance. All estimates are standardized, except those for the loadings, the means, and the variances associated with intercepts and slopes. ${ }^{*} p<.05 .{ }^{* *} p .01$.

intercepts, all the coefficients linking the two slopes to the intercepts, the path predicting the slope of hierarchical level from that of job performance, and the effects of the covariates. This highly constrained model fitted the data well $\mathrm{SB}^{2}(590, N=563)=1207.82, p<.0001$, $\mathrm{CFI}=0.935$, TLI $=.928, \mathrm{RMSEA}=0.062(0.056,0.066)$, and was trivially different from the unconstrained model: $\mathrm{SB} \Delta \chi_{(60)}^{2}=39.80$, DCFI $=-.001$, DRMSEA $=-.001$, thus suggesting these various estimates do not vary between men and women. In other words, performance change is important for promotion regardless of employee gender.

\section{Discussion}

Although previous conceptualizations hint at the fact that performance-promotion processes unfold over time, these previous models have largely been static. But several theoretical perspec- 
tives point to the importance of performance change in organizational decisions. The purpose of Study 1 was to develop and test a dynamic model of performance-promotion relationships. We began with the premise that increases in job performance are perceived to have implications for organizational success, and thus such increases should be rewarded. A common form for such rewards is promotion. Although many previous studies have examined performance-promotion linkages, relationships between changes in job performance and changes in workers' position in the organization have been neglected. Thus, we developed a model linking changes in workers' job performance to changes in hierarchical level over time.

We tested this model with a unique longitudinal dataset comprising both (a) a measure of job performance that was consistent across hierarchical levels and (b) objective data regarding the hierarchical level of a large sample of workers assessed four times over six years. Consistent with previous, we found that performance and hierarchical level intercepts were, at best, weakly related. As has been found in the past, those with high performance at a given time point were no more likely to be high in hierarchical level than were those with low performance at that time point.

The hypothesis of primary interest revolved around the relationship between change in performance and change in hierarchical level (H1). Consistent with this hypothesis, change in performance predicted change in hierarchical level over and above initial performance level. Specifically, the greater the improvement in performance over previous time points, the greater the increase in hierarchical level at subsequent time points, holding initial performance constant. Thus, ours is the first study to show that promotion decisions are based not only on performance level, but also on performance trajectory. In other words, consistent with prospect theory, spiraling theory, and sponsored and contest mobility theory, performance trends are both salient and influential to those making promotion decisions.

We also examined gender as a possible moderator of relationships in our model. Interestingly, and differently from Lyness and Heilman (2006), gender was unrelated to intercepts, slopes, or the relationships among them. This suggests that performance trend does not trigger the same biases as does performance level. Having established that decision makers notice and attach weight to performance trend, the question that remains is, what are the virtues that supervisors ascribe to those with upward performance trends that lead those supervisors to promote them? We explore this question in Study 2.

\section{Study 2}

In this study, we explore the attributions that cause decision makers to predict higher future performance for those with positive performance trends, which in turn leads to assessments of promotability. Consider once again the performance trajectories of the four employees in Figure 1. The results of Study 1 suggest that, contrary to traditional models, employee A is unlikely to be chosen for promotion because, in spite of his or her superior performance, his or her trend is inferior to that of the other candidates. In Study 2 , we examine why this might be.

What little research that exists on the qualities that are ascribed by others to those with different performance trends has tended to focus on relatively global attributes. Most notably, Reb and Greguras (2010) found that those with positive trends were rated higher on both ability and effort. This is, in fact, consistent with research on the determinants of actual performance improvement. Kanfer and Ackerman (1989), as well as Murphy (1989) posited that performance changes over time are due to individual differences in ability and in dispositional variables related to motivation. Others have suggested that employees improve their performance levels because they have learned more efficient ways of doing a task (Sturman \& Trevor, 2001), because they are devoting more attention to their jobs (Kanfer \& Ackerman, 1989), or because they have the ability to learn new tasks and to handle challenging job demands (Deadrick, Bennett, \& Russell, 1997). Those with managerial experience may have observed these sorts of traits in employees who have improved their performance in the past. If so, then they might be expected to project these sorts of ability- and effort-related virtues onto those with upward performance trends.

Promotion decisions are essentially forecasts of future career success. Because ability and effort attributions are perceived as not only virtuous, but also stable, they would be seen as highly relevant for such a decision-making process. In support of this notion, $\mathrm{Ng}$ et al. (2005) showed that conscientiousness, proactivity, and cognitive ability were all significant predictors of promotion.

On the other hand, Reb and Greguras (2010) found that, whereas performance level was the primary determinant of perceived ability, performance trend was the primary determinant of perceived effort. This suggests that the reason that performance trend contributes to the prediction of promotion decisions beyond performance level is that it triggers effort-related attributions that performance level does not.

That said, one theme that arises time and again is that decision makers ascribe ability to high performers. Breaugh (2011) states that "past performance is likely to be seen as an indicator of the person's ability" (p. 267). Ng et al. (2005) include cognitive ability as one of their "stable individual difference variables" that predict career success. In fact, ability attributions are associated with past performance even in some of the earliest attributional models (e.g., Heider, 1958). If we extrapolate from this prior work together with work linking ability to knowledge and skill acquisition (Ackerman, Kanfer, \& Goff, 1995; Day, Arthur, \& Gettman, 2001), we can see that an upward performance trend should suggest to decision makers that the subordinate possesses the ability necessary to acquire the skills that are required for performance improvement. This is consistent with work on knowledge and skill acquisition (Ackerman et al., 1995; Day et al., 2001), predictors of career success over time (Judge, Klinger, \& Simon, 2010), and performance in what Murphy (1989) calls the transition stage. Therefore, we hypothesize that decision makers would associate a high level of ability with an upward performance trend.

Hypothesis 2a: Positive performance trends are associated with higher perceived levels of ability.

Besides ability, performance trends also send signals about effort or motivation. Like ability, motivation appears in some of the earliest attribution models (e.g., Heider, 1958). Scott and Hamner (1975) found that workers showing improvement were rated as more motivated than those who did not show such a 
pattern or whose pattern of performance was deteriorating over time. The term also comes up repeatedly in Breaugh's (2011) model of the promotion process. It emerges in several of the factors uncovered in the Longenecker and Fink (2008) interviews with hiring managers where we often see an emphasis on motivation to perform one's job at a high level, that is, job dedication. Job dedication reflects "working harder than necessary" and "persisting in overcoming obstacles to task completion" (Findley, Giles, \& Mossholder, 2000). An upward performance trend should be especially suggestive of job dedication because it is dedication that allows the person to overcome early obstacles to productivity and to maintain effort in the face of early failure. A downward trend, by contrast, should convey declining dedication given that the person has already demonstrated that they have the ability to perform at a higher level.

Hypothesis 2b: Positive performance trends are associated with higher perceived levels of job dedication.

Effort and motivation can be attributed to dispositional factors (Cortina \& Luchman, 2013), in particular, conscientiousness. Conscientiousness refers to the tendency to be orderly, organized, reliable, careful, goal directed, and diligent at work (Judge et al., 1999). Conscientious people are achievement-oriented, dependable, orderly, and cautious (Stewart, 1999). Research has shown that conscientiousness positively predicts effort (Noftle \& Robins, 2007) and leads to improvements in academic performance (Zyphur, Bradley, Landis, \& Thoresen, 2008) and sales performance (Thoresen, Bradley, Bliese, \& Thoresen, 2004). Conscientiousness is another of the stable factors examined by $\mathrm{Ng}$ et al. (2005) as a predictor of promotion. It also comes up in multiple places in the Longenecker and Fink (2008) interviews. Particularly relevant for trend-related attributions, these authors concluded that decision makers view the maintenance of long-term performance track records as unlikely for those that they perceive to be undependable or incautious. The flip side of this is that positive performance trends should suggest things like dependability as such trends would not have been possible without it. Such reasoning can be extended to other facets of conscientiousness such as achievement and order.

Hypothesis 2c: Positive performance trends are associated with higher perceived levels of conscientiousness.

Another dispositional factor that is highly relevant to the motivation to learn and improve is proactive personality (Seibert et al., 1999). Proactive personality represents a stable behavioral tendency to behave proactively toward situations, such as identifying improvement opportunities and enacting changes to improve current circumstances (Bateman \& Crant, 1993). Research has shown that individuals high in proactive personality are successful in preparing for career-related changes and obtaining career success (Seibert et al., 1999). Proactive personality is especially relevant for our purposes because it taps into effort-related behavior patterns that are, nevertheless, distinguishable from other personality variables such as conscientiousness. Proactive employees tend to seek out problems to solve, and when faced with environmental constraints they tend to remove the constraints rather than adapt to them. Employees who are merely, say, high in conscientiousness may, nevertheless, wait for problems to come to them and adapt rather than transform the environment.

Because individuals high in proactive personality often demonstrate an improving performance trend, managers who have observed such associations in the past are likely to attribute an upward performance trend to a high level of proactive personality as well. Longenecker and Fink (2008) report that the sort of person who is good at "fixing things", "solving problems," and "removing organizational roadblocks" is seen as likely to "develop additional skills" and suggests that the person can, "not only perform well at their current level but also [is] capable of performing on a larger stage" (p. 248). An upward performance trend should signal proactive personality, because performance improvement suggests that the person can "fix" or "solve" the problems that had been limiting their performance initially, and that they were able to remove the "roadblocks" to their own success. Conversely, failure to go upward suggests that the person is easily discouraged or defeated by roadblocks, that is, low proactive personality.

Hypothesis 2d: Positive performance trends are associated with higher perceived levels of proactive personality.

It should be mentioned that there are many other factors that are likely to figure into predictions of future performance. For example, Breaugh (2011) mentions social skills, Longenecker and Fink (2008) mention teamwork skills, and so on. We included only those constructs the perception of which might be influenced by performance trend. Although social and teamwork skills are certainly important given increasingly common network organizational structures, it isn't clear why decision makers would ascribe such skills to those with a particular performance trend. In addition, these other skills are more job specific than are the factors that we included. We were interested only in those factors that might be signaled by performance trend regardless of the nature of the job or industry.

As we argue above, decision makers tend to ascribe positive ability- and effort-based attributes to people with positive performance trends. Because these virtuous attributes are stable, decision makers would believe that these attributes would still be present in the future (i.e., naïve extrapolation; Ariely \& Carmon, 2003). As a result, they would expect people with positive performance trends to have high future performance. This would be the basis for recommending such people for promotion. Therefore, we hypothesize the following:

Hypothesis 3a: Performance trend predicts expected future performance through its effects on perceived ability

Hypothesis 3b: Performance trend predicts expected future performance through its effects on job dedication

Hypothesis 3c: Performance trend predicts expected future performance through its effects on conscientiousness

Hypothesis 3d: Performance trend predicts expected future performance through its effects on proactive personality.

Finally, our various hypotheses can be combined as follows:

Hypothesis 4: Performance trend is linked to promotability in a set of chain mediations with trend influencing the four 
transmitters mentioned above which, in turn, affect expected future performance, which then affects promotability.

Figure 4 assembles our hypotheses in a single model.

\section{Method}

Sample. Study 2 was an experiment conducted with 233 employed adults with supervisory experience from Amazon's Mechanical Turk (MTurk). In keeping with recommended practices, employment status and supervisory experience were ensured not by screening out potential respondents who did not qualify, but rather by asking all respondents about their age, employment status, and supervision experience. This removes the incentive to misrepresent oneself (Chandler \& Paolacci, 2017). To ensure data quality, at the beginning of the survey we explicitly instructed participants that they would not be eligible for compensation if they failed to read instructions or respond carefully. We asked participants to report their age, employment status, and the number of people they supervised both at the beginning and at the end of the survey. We also included instructed items (i.e., participants were instructed to select a given response), which were spread out throughout the survey.

Procedure. Participants were presented with a graph containing overall performance evaluations for each of three fictitious people at each of four time points evenly spaced over the past 18 months. The performance evaluation of Person X was high at Time 1 but had dropped steadily. The evaluation of Person Y was lower at first but remained constant over time. The evaluation of Person $\mathrm{Z}$ began very low but increased at the same rate that the performance of Person $X$ decreased. At Time 4, the rank order was still $\mathrm{X}, \mathrm{Y}, \mathrm{Z}$. Of most importance for present purposes is that, although the rank order of the three candidates in terms of performance trend is $\mathrm{Z}, \mathrm{Y}, \mathrm{X}$, their rank order in terms of performance level (current or average) is the opposite. This offers the opportunity for a stronger test of the effect of trend in that, if candidate $\mathrm{Z}$ is rated higher on future performance expectations, promotability and so forth, it is in spite of what is clearly an inferior performance level.

Participants were asked to study the graph and to then rate $\mathrm{X}, \mathrm{Y}$, and $\mathrm{Z}$ with regard to conscientiousness, proactive personality, job dedication, and ability. They were also asked to rate future performance expectations and promotability for each person. Thus, this was a within-subject experimental design with six dependent variables. It should be noted that respondents were asked to rate the attributes of the targets before they were aware that they would be asked about future performance and promotability.

Measures. Conscientiousness was measured with the nineitem BFI (see John, Naumann, \& Soto, 2008 for descriptions of scale development and validation). Proactive personality was measured with the shortened 6-item version of Bateman and Crant's (1993) proactive personality scale, validated by Parker (1998). Job dedication was measured with the eight-item scale developed and validated by Van Scotter and Motowidlo (1996). Ability was measured with five of the six items in the perceived ability scale developed and validated by Mayer and Davis (1999). One item was dropped because it dealt with success rather than ability ("[This person] is known to be successful at the things [he/she] tries to do"). Future performance expectations were measured with the four-item task-performance scale developed and validated by Liden, Wayne, and Stilwell (1993). Items were adapted to reflect future performance instead of past performance. We also asked these four questions a second time to measure participants' judgment about each person's past performance. Responses to these questions were used to identify careless responders as explained below. Promotability was measured with four items, including the three-item scale developed and validated by Thacker and Wayne (1995) and one item reflecting readiness for promotion from Van Scotter, Motowidlo, and Cross (2000). This last item was added because we wanted the scale to capture overall preparedness for the next level. All items were measured with a 5-point Likert scale. Cronbach's alphas and omega-h values are reported in Table 4.

Data cleaning. We followed recommended practices for identifying careless survey responders (Meade \& Craig, 2012). We collected data from 416 MTurkers. Fifteen were dropped because of more than half of their survey responses were missing. After excluding participants who were not at least 18 years old, reported that they were currently unemployed or had no supervision experience, or did not report the same responses on age, employment status or number of people they supervised pre-post, 283 participants remained. Twenty-three were dropped because they failed to select the instructed response on at least one item. Four were dropped because their responses were identified as univariate outliers and resulted in impossible responses to the past performance items (i.e., ratings of 1 for person $\mathrm{X}$ or ratings of 5 for person Z). Twelve were dropped because they responded with the same answer on 20 or more consecutive questions. Finally, another 11 were dropped because they were identified as multivariate outliers as evidenced by Mahalanobis distance. This left us a final sample of 233 participants who provided compete data and showed no signs of careless responding, a retention rate that is typical for this type of study (Necka, Cacioppo, Norman, \& Cacioppo, 2016).

\section{Results}

Table 4 contains descriptive statistics for all variables, including two dummy variables to capture the 3 conditions of the performance trend variable. ${ }^{8}$ Pearson correlations are reported for DVs, Fn8 whereas partial correlations are reported for the dummy variables because they reflect the difference, in correlational terms, between the referent in question and the uncoded referent (Cohen, Cohen, West, \& Aiken, 2003, p. 316). As can be seen, both the Dummy X variable (i.e., $\mathrm{X}=1$; $\mathrm{Y}$ and $\mathrm{Z}=0$ ) and the Dummy $\mathrm{Y}$ variable (i.e., $\mathrm{Y}=1 ; \mathrm{X}$ and $\mathrm{Z}=0$ ) correlated significantly and negatively with all measured variables. These negative correlations show that respondents rated person $\mathrm{Z}$ (i.e., with ascending performance trend) higher than person $X$ (descending trend) on all study variables. Person $\mathrm{Z}$ was also judged higher on all DVs than person $\mathrm{Y}$ (flat trend), although the difference was not as large as that between person $\mathrm{X}$ and person $\mathrm{Z}$.

\footnotetext{
${ }^{8}$ Tables 4, 7, and 10 contain, among things, both alpha and omega-h values averaged across stimuli. Omega-h values can be smaller than alpha values if there are sizeable group factors relative to the general factor. This appears to be the case for the BFI (conscientiousness) because it includes negatively worded items. We were reluctant to modify the scale, however, because this version has been validated in several studies by John and others. The presence of group factors also suggests that one shouldn't attach too much significance to the alpha values for the BFI. We report them here because convention demands that we do so.
} 


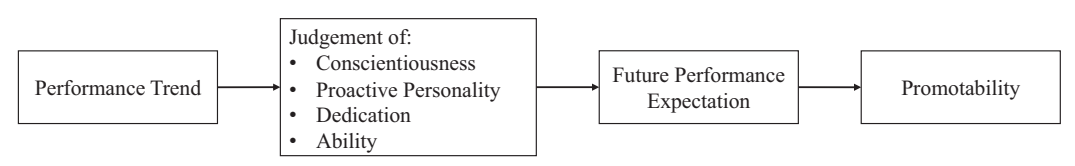

Figure 4. Hypothesized linkages among performance trend, judgments, future performance expectation, and promotability.

Before moving on to tests of hypotheses, it is interesting to note the differences in alpha (and omega-h) values across targets. Although most of these values are consistent with previous research using these scales, on all judgment variables, they are higher for person $\mathrm{X}$ and person $\mathrm{Z}$ than for person $\mathrm{Y}$. This is consistent with the notion that performance patterns that demonstrate a clear trend (i.e., higher velocity) send a clearer signal about certain attributes than do others. As a matter of interest, we conducted tests of significance for the differAQ: 10 ence between dependent coefficient alphas (Feldt, Woodruff, \& Salih, 1987) for Person $Z$ (the ascending trend) versus Person Y (the flat trend). We found that alpha was significantly higher for Person $\mathrm{Z}$ for future performance, $t=5.61, p<.01$, conscientiousness, $t=6.89$, $p<.01$, proactive personality, $t=2.70, p<.01$, dedication, $t=3.11$, $p<.01$, and ability, $t=3.13, p<.01$. Although the alpha coefficient for promotability for Person Y was also lower than for Person Z, the difference was not statistically significant, $t=1.16, p>.05$. In short, it seems that respondents know (or think they know) what to make of an upward trend, but they are less clear on the attributes of targets with flat trends.

To test our theoretical model, we ran a multilevel path model in Mplus 8.3, with observations nested within subject. Results of these analyses are contained in Tables 5 and 6 and Figure 5. First, hypotheses $\mathrm{H} 2 \mathrm{a}-\mathrm{H} 2 \mathrm{~d}$ were all supported. Mean conscientiousness was rated 0.74 lower for person $\mathrm{X}$ than for person $\mathrm{Z}$, and it was 0.20 lower for person $\mathrm{Y}$ than for person $\mathrm{Z}$. Mean proactive personality was rated 1.04 lower for person $\mathrm{X}$ than for person $\mathrm{Z}$, and it was 0.70 lower for person $Y$ than for person $Z$. Mean dedication was rated 1.14 lower for person $\mathrm{X}$ than for person $\mathrm{Z}$, and it was 0.68 lower for person $Y$ than for person Z. Lastly, mean ability was rated 0.88 lower for person $\mathrm{X}$ than for person $\mathrm{Z}$, and it was 0.43 lower for person $\mathrm{Y}$ than for person $\mathrm{Z}$. All effects were significant at the 0.01 level (SEs reported in Table 5).

These results are unlikely to be attributable to demand characteristics vis-a-vis performance trends simply because Persons X,
$\mathrm{Y}$, and $\mathrm{Z}$ also differed in current and mean performance such that Person $\mathrm{X}$ was highest on both, followed by $\mathrm{Y}$ and $\mathrm{Z}$. If anything, the demand characteristics of performance mean and trend might be expected to cancel one another out. Instead, respondents ascribed virtues to person $\mathrm{Z}$ in spite of their having the lowest level of performance.

Next, hypotheses H3b, H3c, H3d were supported. Ratings of job dedication, conscientiousness, and proactive personality contributed positively to the prediction of expectations of future performance. When combined with the tests of $\mathrm{H} 2 \mathrm{~b}, \mathrm{H} 2 \mathrm{c}$, and $\mathrm{H} 2 \mathrm{~d}$, we can conclude that these variables transmit the effects of trend onto future performance expectations. Hypothesis $\mathrm{H} 3 \mathrm{a}$ was not supported, suggesting that effort-related variables are seen as more relevant for success in a new position than is ability. Finally, future performance expectations predicted promotability. We also tested the indirect effects of performance trends through the three significant predictors of future performance expectations. These ranged from -.037 to -.484 and were all statistically significant and in the expected direction. 95\% confidence intervals (CIs) around indirect effects were constructed following the Monte Carlo simulation approach recommended by Selig and Preacher (2008). As can be seen in Table 6, none of the CIs contained zero.

Putting this together, three of our four chain mediation hypotheses were supported. Trends relate to promotability judgments because they signal information about conscientiousness, proactive personality, and job dedication. Positive trends suggest higher levels of these characteristics, which in turn lead to the future performance expectations that drive promotion.

\section{Supplemental Analysis}

Barnes, Reb, and Ang (2012) explored the possibility that basketball General Managers place too much emphasis on perfor-

Table 4

Descriptive Statistics, Cronbach's Alpha and Omega $h$ Values, and Intercorrelations for Study 2

\begin{tabular}{|c|c|c|c|c|c|c|c|c|c|c|}
\hline Variable & $M$ & $S D$ & 1 & 2 & 3 & 4 & 5 & 6 & 7 & 8 \\
\hline 1. Future performance & 3.30 & 0.99 & $(.89, .88)$ & & & & & & & \\
\hline 2. Promotability & 3.32 & 1.04 & $.86^{* *}$ & $(.88, .88)$ & & & & & & \\
\hline 3. Conscientiousness & 3.25 & 0.76 & $.63^{* *}$ & $.64^{* *}$ & $(.82, .66)$ & & & & & \\
\hline 4. Proactive personality & 3.39 & 0.89 & $.79^{* *}$ & $.82^{* *}$ & $.67^{* * *}$ & $(.90, .89)$ & & & & \\
\hline 5. Dedication & 3.42 & 0.95 & $.78^{* *}$ & $.80^{* *}$ & $.66^{* *}$ & $.87^{* *}$ & $(.93, .94)$ & & & \\
\hline 6. Ability & 3.60 & 0.85 & $.70^{* *}$ & $.74^{* *}$ & $.72^{* *}$ & $.79^{* *}$ & $.83^{* *}$ & $(.87, .87)$ & & \\
\hline 7. Dummy X & 0.33 & 0.47 & $-.50^{* *}$ & $-.45^{* * *}$ & $-.42^{* *}$ & $-.41^{* *}$ & $-.42^{* * *}$ & $-.33^{* *}$ & - & \\
\hline 8. Dummy Y & 0.33 & 0.47 & $-.29^{* * *}$ & $-.30^{* * *}$ & $-.13^{* *}$ & $-.30^{\text {*** }}$ & $-.28^{* * *}$ & $-.16^{* * *}$ & $-.50^{\text {*** }}$ & - \\
\hline
\end{tabular}

Note. Level $1 N=699$. All variables were within individual (Level 1) variables. Dummy X: coded as 1 for Person X (with descending performance trend), 0 otherwise; Dummy Y: coded as 1 for Person Y (with flat performance trend), 0 otherwise. Cronbach's alpha and McDonald's omega-h (averaged across the three stimuli) are reported on the diagonal, with alpha on the left and omega-h on the right. *** $p<.01$. 
Table 5

Multilevel Path Coefficients: Performance Trend Predicting Personality Trait Judgments (Study 2)

\begin{tabular}{lcccc}
\hline Variable & Conscientiousness & Proactive personality & Dedication & Ability \\
\hline Dummy X & $-.74^{* *}(.10)$ & $-1.04^{* * *}(.05)$ & $-1.14^{* *}(.05)$ & $-.88^{* * *}(.05)$ \\
Dummy Y & $-.20^{* *}(.06)$ & $-.70^{* * *}(.04)$ & $-.68^{* *}(.04)$ & $-.43^{* * *}(.04)$ \\
$R^{2}$ & $.25^{* *}$ & $.41^{* * *}$ & $.41^{* * *}$ & $.30^{* * *}$ \\
\hline
\end{tabular}

Note. Values are unstandardized regression coefficients ( $E E$ estimates listed in parentheses).

*** $p<.01$.

mance means and trends by regressing compensation (the primary dependent variable of their study) onto mean and trend controlling for future performance. They found that although the effect of performance mean disappeared when future performance was entered as a control, the effect of trend did not, suggesting that, "compensation managers place an irrationally high amount of weight [on performance trend]" (Barnes et al., 2012, p.715). With regard to the present study, one might consider it even more irrational if decision maker's evaluation of promotability were predicted by performance trend controlling for their own expectations of future performance.

To examine this possibility, we tested a hierarchical multilevel regression model regressing promotability onto the performance trend dummy variables controlling for future performance expectations. Results showed that performance trends had a significant influence on promotability judgments, above and beyond the influence of expected future performance. Specifically, after controlling for the influence of future performance expectations, the mean rating of promotability was 0.15 lower for person $\mathrm{Y}$ than for person $\mathrm{Z}(p<.01)$. The mean rating of promotability was 0.04 lower for person $\mathrm{X}$ than for person $\mathrm{Z}$ but the difference was not significant. These supplementary analyses suggest that decision makers may in fact attach too much importance to performance trends.

\section{Discussion}

The purpose of Study 2 was to use an experimental design to identify the promotion-related attributions that raters make on the basis of performance trend. Study 2 examined the perceived attributes that lead decision makers to forecast success for those with upward performance trends. In Study 2, we found once again that performance trend was related to promotion-related judgments. More importantly, Study 2 showed that the candidate with the positive trend was judged to be higher on various promotionrelated attributes in spite of the fact that this candidate had the lowest performance level. Study 2 results also suggest that although raters do make both ability-related and effort-related attributions on the basis of performance trend, it is the effort-related attributions that result in higher expectations of future performance and promotability. Specifically, it is the judgments of the candidate's conscientiousness, job dedication, and proactive personality that transmit the effect of performance trend onto performance expectations and promotability. If we combine these findings with those of Reb and Greguras (2010), we would conclude that decision makers set a great deal of store by the factors that they associate with effort and that they perceive higher levels of these factors in those that have upward performance trends even if their

Table 6

Multilevel Path Coefficients: Personality Trait Judgments Predicting Future Performance Expectation and Promotability (Study 2)

\begin{tabular}{lcc}
\multicolumn{1}{c}{ Variable } & Future performance expectation & Promotability \\
\hline Conscientiousness & $.18^{* *}(.07)$ \\
Proactive personality & $.47^{* *}(.07)$ & \\
Dedication & $.32^{* * *}(.07)$ & $.94^{* * *}(.02)$ \\
Ability & $.05(.06)$ & $.75^{* * *}$ \\
Future performance expectation & $.66^{* *}$ & \\
$R^{2}$ & & \\
Indirect effects of Dummy X on future & & \\
$\quad$ performance expectation & & \\
Through conscientiousness & & \\
Through proactive personality & $-.136,[-0.2325,-0.0354]$ \\
Through dedication & $-.366,[-0.5409,-0.3429]$ \\
Indirect effects of Dummy Y on future & \\
$\quad$ performance expectation & & \\
Through conscientiousness & & \\
Through proactive personality & $-.037,[-0.0706,-0.0094]$ \\
Through dedication & $-.25,[-0.4284,-0.2284]$ \\
\hline
\end{tabular}

Note. Values are unstandardized regression coefficients ( $S E$ estimates listed in parentheses). All intervals are 95\% confidence intervals based on 20,000 Monte Carlo simulations.

*** $p<.01$. 


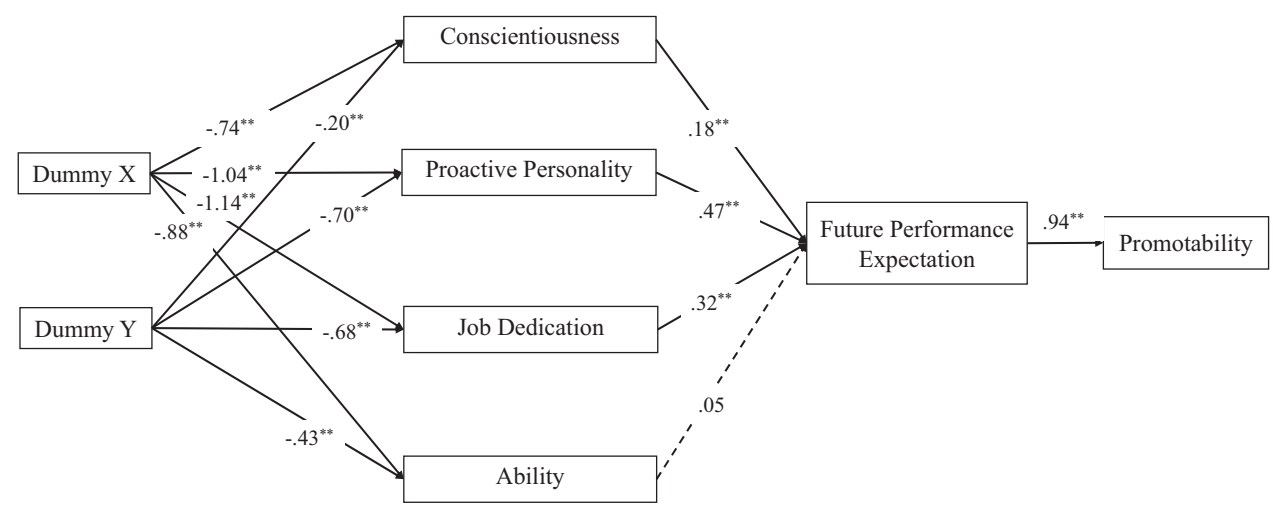

Figure 5. The path model (Study 2). All path coefficients are unstandardized. Dashed lines indicate nonsignificant paths. Dummy X: judgments of person $\mathrm{X}$ (with descending performance trend) were coded as 1, 0 otherwise; Dummy Y: judgments of person Y (with flat performance trend) were coded as 1,0 otherwise. ${ }^{* *} p<$ .01 .

performance levels have not yet reached the levels of others. Furthermore, it would seem that decision makers see these factors as stable and, therefore, useful for future performance.

\section{Study 3}

Study 2 was deliberately designed to stack the deck against the upward performance trend. The fact that decision makers preferred the person with the upward trend anyway speaks to the importance of such trends. Our design choices did, however, prohibit us from fully crossing the level and trend variables. In Study 3, therefore, we crossed these variables to test for level by trend interactions. Specifically, we used a $2 \times 2$ within-subjects design in which the trend was either upward or downward and the final performance level was either high or low. We chose to manipulate final rather than initial performance level so that the downward performance trend would have a higher average performance than the upward trend within performance level. This also allowed us to examine the effect of trend on judgments of future performance beyond an individual's most recent performance level, which serves as a more proximal reference point that drives people's perceptions (see Hausknecht, Sturman, \& Roberson, 2011; Park, Sturman, Vanderpool, \& Chan, 2015 for more discussion on this).

Finally, because there might be transmitters of trend effects in addition to those included in Study 2, we also added measures of job identity and commitment. ${ }^{9}$ Welbourne and Paterson (2017) define job identity as, "the degree to which an individual's job (e.g., the parts of the job that are described in formal job descriptions) is central to overall identity or self-definition." (p.323). Just as decision makers would attribute an upward performance trend to one's dedication to one's job, so might they attribute such trends to ties between one's job and one's self concept. Given the conceptual overlap between job dedication and job identity, it is unlikely that both contribute to prediction of assessments of future performance and promotability. Nevertheless, it is important to discover which is the stronger transmitter of the effects of trend.

The affective component of organizational commitment (referred to as commitment hereafter), reflects an employee's "emotional attachment to, identification with, and involvement in the AQ: 11 organization" (Meyer \& Allen, 1991; p. 67). People with high commitment are thought to contribute to organizational effectiveness by exerting more effort in their jobs (Meyer, Allen, \& Smith, 1993), going beyond formal responsibilities and into extra role behaviors (Shore \& Wayne, 1993). Because of this, decision makers would be likely to attribute an upward performance trend to high levels of effort because of high commitment to the organization. These attributions could then lead to high expectations regarding future performance and promotability.

\section{Method}

The methods were similar to those of Study 2. As with Study 2, a within-subject experiment was conducted on MTurk with all subjects responding to survey items in response to different performance level-trend combinations. Unlike Study 2, end level and trend were fully crossed such that each respondent evaluated a high end level-downward trend employee, a high end level-upward trend employee, a low end level-downward trend employee, and a low end level-upward trend employee. Both high level employees had trends that ended at the same level, as did both low level employees.

The same measures of conscientiousness, proactive personality, dedication, future performance expectation, and promotability ${ }^{10}$ Fn10 were used in Study 3. Job identity was assessed with the two-item measure validated in Welbourne and Paterson (2017). Commitment was assessed with the three positively worded items from Meyer et al.'s (1993) measure of affective commitment. All items were measured with a 5-point Likert scale. We followed the same procedure in Study 2 for data collection and cleaning. Data were collected from a total of 554 MTurkers. After applying the same exclusion criteria as in Study 2, a final sample of 256 remained for analysis.

\footnotetext{
${ }^{9}$ We thank an anonymous reviewer who suggested that we add these measures.

${ }^{10}$ Ability was not included because it was not found to be a significant predictor of future performance judgments in Study 2 .
} 


\section{Results and Discussion}

Table 7 contains descriptive statistics for all variables as well as intercorrelations among them. All Cronbach's alpha values were .84 or greater, suggesting adequate internal consistency reliability. As can be seen, performance trend correlated significantly and positively with all measured variables, indicating that the ascending performance trends were rated more positively than the descending trends. Final performance level also correlated significantly and positively with ratings of future performance, promotability, conscientiousness, proactive personality, and dedication, but not with job identity and commitment. In addition, correlations between measured variables and final performance level were all substantially smaller than were the correlations with performance trend.

As in Study 2, we ran a multilevel path model in Mplus 8.3, with targets nested within subject. Results of these analyses are reported in Tables 8 and 9 and Figure 6. As can be seen, performance level and performance trend each significantly and positively predicted judgments of conscientiousness, proactive personality, dedication, job identity, and commitment, controlling for the influence of the other. These results suggest that people with higher final performance levels and ascending trends were seen as higher on these five characteristics. Further, ratings of conscientiousness, proactive personality, job dedication, and commitment all contributed positively to the prediction of expectations of future performance. Contrary to expectation, job identity did not significantly predict judgments of future performance $(B=.06, S E=.03, p=.06)$. This may be because identity correlated with predictors that had stronger relationships with future performance. Finally, future performance expectations significantly predicted promotability.

The indirect effects of performance trend and level on future performance expectations through the four significant predictors were tested with Selig and Preacher's (2008) Monte Carlo simulation approach. Results suggest that indirect effects of performance trend ranged from .134 to .466 , with dedication being the strongest transmitter. Indirect effects of performance level ranged from .016 to .062 and dedication again was the strongest transmitter. The indirect effects of performance trend were all larger than those of performance level.

These results add to our findings in Study 2. After controlling for final performance level, performance trend contributes substantially to the prediction of future performance and promotability judgments. Specifically, a positive trend suggests higher levels of judgments of conscientiousness, proactive personality, job dedication, and commitment, which in turn lead to higher expectations of future performance. These expectations then predict promotion decisions. Results also showed that the effects of performance trend were much larger than those of performance level.

Finally, the factorial design allowed us to examine the possibility that performance level and trend interact in influencing judgments of target attributes. None of the interaction terms was significant, ${ }^{11}$ suggesting that the effect of performance trend on target attributes does not depend on performance level.

\section{Study 4}

Studies 2 and 3 showed that respondents ascribed more promotionrelevant virtues to targets with upward performance trends even when the performance levels of these targets were lower than those of targets with downward trends. In Study 3, we found no evidence that the effect of trend depends on performance level.

In a Study 4 we investigated the limits of the power of trend by comparing a target with an upward trend to one that had a flat trend, a higher average, and a higher endpoint. Specifically, the endpoint for the higher target was half a point higher than the endpoint for the lower target on a 10 point scale. This allowed us to explore the possibility that respondents in Studies 2 and 3 were marking down the target with the downward trend more than they were marking up the target with the upward trend. In other words, we wished to compare a target who started lower but was improving to a target who was consistently high.

\section{Method}

The methods were identical to those of Study 2 except that there were only two targets: one with a trend starting at 5 and continuing upward toward 7, and the other flat at 7.5, on a 10-point performance rating scale. As with Study 3, a within subject experiment was conducted on MTurk with all subjects responding to the two performance profiles mentioned above. Measures were the same as those in Study 3. Data were initially collected from 404 MTurkers, and 220 remained in the final sample after applying the same exclusion criteria as in Study 3.

\section{Results and Discussion}

Table 10 contains descriptive statistics for all variables as well T10 as intercorrelations among them. Specifically, the dummy variable profile ( 1 = flat trend, high level; 2 = ascending trend, low level) significantly and positively correlated with all judgment variables. As with Study 3, we ran a multilevel path model in Mplus 8.3 (results presented in Figure 7). Specifically, the target with low F7 levels of performance but an ascending trend was rated more positively on all five judgment variables (i.e., conscientiousness, proactive personality, job dedication, job identity, and commitment), compared with the other target with high levels of performance but a flat trend. Further, proactive personality and job dedication significantly predicted the evaluation of future performance expectations, which significantly predicted promotability. For the two significant predictors of future performance, indirect effects as well as $95 \%$ confidence intervals (CIs) were computed following Selig and Preacher's (2008) Monte Carlo simulation approach. The indirect effect of performance profile on future performance expectation through proactive personality was $.169,95 \%$ CI $[.099, .251]$. The indirect effect of profile on future performance expectation through dedication was .132, 95\% CI [.058, .214]. These results suggest that once again that respondents judge a target with an upward trend to be higher in future performance. In the case of Study 4, this is in spite of consistently high performance from the other target. And as with Studies 2 and 3, the reason for this judgment was that the target with the upward trend was seen to be higher in proactive personality and job dedication, both of which are stable, effort-related attributes.

\footnotetext{
${ }^{11}$ Conscientiousness: $B=-.00, S E=.03, p=.89$; Proactive Personality: $B=.01, S E=.04, p=.83$; Dedication: $B=.05, S E=.03, p=.14$ Job Identity: $B=-.01, S E=.05, p=.86$; Commitment: $B=.03, S E=$ $.04, p=.47$.
} 
Table 7

Descriptive Statistics, Cronbach's Alpha and Omega-h Values, and Intercorrelations for Study 3

\begin{tabular}{|c|c|c|c|c|c|c|c|c|c|c|c|}
\hline Variable & $M$ & $S D$ & 1 & 2 & 3 & 4 & 5 & 6 & 7 & 8 & 9 \\
\hline 1. Future performance & 3.37 & 1.11 & $(.89, .89)$ & & & & & & & & \\
\hline 2. Promotability & 3.40 & 1.16 & $.90^{* *}$ & $(.89, .91)$ & & & & & & & \\
\hline 3. Conscientiousness & 3.17 & 0.84 & $.76^{* * *}$ & $.78^{* * *}$ & $(.84, .69)$ & & & & & & \\
\hline 4. Proactive personality & 3.49 & 0.98 & $.85^{* * *}$ & $.88^{* *}$ & $.79^{* *}$ & $(.91, .92)$ & & & & & \\
\hline 5. Dedication & 3.49 & 1.08 & $.87^{* *}$ & $.90^{* * *}$ & $.81^{\text {*** }}$ & $.93^{* *}$ & $(.94, .94)$ & & & & \\
\hline 6. Job identity & 3.44 & 1.03 & $.68^{* * *}$ & $.69^{* * *}$ & $.55^{* *}$ & $.71^{* *}$ & $.73^{* * *}$ & $(.85, .85)$ & & & \\
\hline 7. Commitment & 3.45 & 1.03 & $.81^{\text {** }}$ & $.83^{* *}$ & $.71^{* *}$ & $.86^{* *}$ & $.89^{\text {*** }}$ & $.74^{* *}$ & $(.85, .86)$ & & \\
\hline 8. Level & 1.50 & 0.50 & $.08^{* *}$ & $.11^{* * *}$ & $.10^{* *}$ & $.09^{* * *}$ & $.07^{*}$ & .05 & .06 & - & \\
\hline 9. Trend & 1.50 & 0.50 & $.54^{* * *}$ & $.54^{* *}$ & $.58^{* *}$ & $.51^{* * *}$ & $.54^{* * *}$ & $.36^{* *}$ & $.48^{* *}$ & .00 & - \\
\hline
\end{tabular}

Note. Level $1 N=1024$. All variables were within individual (Level 1) variables. Level: coded as 1 for low final performance and 2 for high final performance; Trend: coded as 1 for descending performance and 2 for ascending performance. Cronbach's alpha and McDonald's omega-h, averaged across stimuli, are reported on the diagonal.

${ }^{*} p<.05 . \quad{ }^{* * *} p<.01$.

\section{General Discussion}

Previous research has shown that performance is, at best, a modest predictor of promotion. In the present article, we have shown that performance trend is an important predictor of promotion. Based on several theoretical perspectives, we hypothesized and found that performance trend contributed to the prediction of promotion decisions beyond performance level. Specifically, we found that the standardized partial coefficient for performance change in the prediction of hierarchical level change was .16 $(p<$ .01 ), holding performance level and controls constant. Thus, the performance-promotion relationship is imbued with both static and dynamic components. Put another way, for decision makers, performance is a matter not only of where the ratee is but also of how he or she got there. In Studies 2, 3, and 4, we explored some of the reasons why decision makers would tend to promote those with upward performance trends. In Study 2, we found that, although raters attributed more ability to those with upward trends, ability attributions did not contribute to the prediction of expected future performance beyond perceived job dedication, proactive personality, and conscientiousness. In Study 3, we found once again that respondents saw more promise in the targets with upward trends, and that these three variables mediated the relationship. Furthermore, the effects of trend were not moderated by performance level. Finally, in Study 4, we found that respondents were more optimistic about the target with the upward trend even when compared with a target whose performance was consistently high. Overall, our results suggest that performance trends influence promotion decisions through their effect on stable, effort-related attributions.
Generally speaking, the present studies suggest that there is much to be learned about the performance-promotion relationship from adopting a dynamic approach. We argued that departures from early performance benchmarks would be salient to decision makers, that these departures would lead to attributions regarding the reasons for these departures, and that these attributions would in turn affect judgments of future performance and promotability. Our longitudinal design in Study 1 coupled with the trend-related stimuli in our experiments allowed us to discover that, indeed, performance trends are both salient and influential. In fact, the modest effects of performance on promotion that have been found in previous studies may have been due to the fact that the designs of most of these studies precluded consideration of performance trends.

From a practical perspective, the present findings would be of value to those designing interventions aimed at incentivizing job performance as it shows a strong tendency for those who improve over time to be promoted more quickly than others. Although our study focuses primarily on decision makers, our results also suggest that employees who ignore their performance trajectories do so at their own peril. There is, however, a cynical side to our findings as well. If decision makers are willing to overlook lower performance in those whose performance is improving, or to look askance at high performers whose performance is stagnant, then there may be dangers in overperforming initially. Performing at a high level initially leaves little room for improvement. As a result, the positive change that appears to be so salient to supervisors cannot occur. It may be wise for workers to leave room for improvement, perhaps underperforming initially. Put another way,

Table 8

Multilevel Path Coefficients: Performance Trend and End Level Predicting Promotion-Relevant Virtue Judgments (Study 3)

\begin{tabular}{lccccc}
\hline Variable & Conscientiousness & Proactive personality & Dedication & Job identity & Commitment \\
\hline Trend & $.98^{* *}(.07)$ & $.99^{* *}(.07)$ & $1.17^{* *}(.08)$ & $.74^{* *}(.07)$ & $1.00^{* * *}(.08)$ \\
Level & $.17^{* *}(.03)$ & $.17^{* *}(.03)$ & $.16^{* *}(.03)$ & $.10^{* *}(.03)$ & $.12^{* *}(.03)$ \\
$R^{2}$ & $.35^{* *}$ & $.27^{* *}$ & $.30^{* *}$ & $.13^{* * *}$ & $.24^{* * *}$ \\
\hline
\end{tabular}

Note. Values are unstandardized regression coefficients ( $S E$ estimates listed in parentheses). *** $p<.01$. 
Table 9

Multilevel Path Coefficients: Promotion-Relevant Virtue Judgments Predicting Future Performance Expectation and Promotability (Study 3)

\begin{tabular}{lcc}
\hline \multicolumn{1}{c}{ Variable } & Future performance expectation & Promotability \\
\hline Conscientiousness & $.19^{* * *}(.04)$ \\
Proactive personality & $.26^{* * *}(.06)$ \\
Dedication & $.40^{* *}(.07)$ & $.06(.03)$ \\
Job identity & $.13^{* *}(.05)$ & $.94^{* * *}(.01)$ \\
Commitment & \\
Future performance expectation & $.190,[.104, .282]$ \\
Indirect effects of trend on future performance expectation & $.261,[.144, .386]$ \\
$\quad$ Through conscientiousness & $.466,[.304, .637]$ \\
Through proactive personality & $.134,[.042, .232]$ \\
Through dedication & $.033,[.017, .053]$ \\
Through commitment & $.045,[.023, .071]$ \\
Indirect effects of level on future performance expectation & $.062,[.035, .094]$ \\
Through conscientiousness & $.016,[.004, .032]$ \\
Through proactive personality & $.78^{* * *}$ \\
Through dedication & \\
Through commitment & \\
$R^{2}$ & \\
\hline Note. Values are unstandardized regression coefficients $(S E$ estimates listed in parentheses). All intervals are \\
$95 \%$ confidence intervals based on 20,000 Monte Carlo simulations. \\
*** $p<.01$.
\end{tabular}

a high reference point leaves little room for a positive subjective value function and the effort-related attributions that are attached to it. In any case, it seems important to train supervisors to be sensitive to all aspects of performance and performance change, including high initial performance paired with lack of change. If such information were incorporated into decision support systems (Sturman, Hannon, \& Milkovich, 1996), managers might avoid the mistake of punishing those who were determined to excel from the outset.

Our findings have considerable theoretical implications as well. Our focus was on performance change as a predictor, but many other predictors of promotion/hierarchical level have been examined in the past, and little of this work has been based on dynamic models. For example, $\mathrm{Ng}$ et al. (2005) found that willingness to transfer and international experience were unrelated to promotion. But perhaps a focus on upward (or downward) trajectories in these attributes would paint a different picture. For the same reasons that change in performance is salient for supervisors (e.g., comparisons to reference values as per prospect theory), so might be change in willingness to transfer or international experience be salient.

\section{Future Directions}

As we mentioned at the outset, our article is primarily descrip- AQ: 12 tive. We found that, when choosing whom to promote, decision makers attach importance to performance trajectory-possibly too much importance. The prescriptions that flow from this observation depend upon the degree to which performance trends really do predict performance in a higher-level job. If future research shows that those with upward trends perform better in higher-level positions than do those with flat or downward trends, then we would prescribe continuation of current tendencies. If instead future research shows, for example, that trend contributes nothing to prediction of performance in higher-level jobs beyond performance

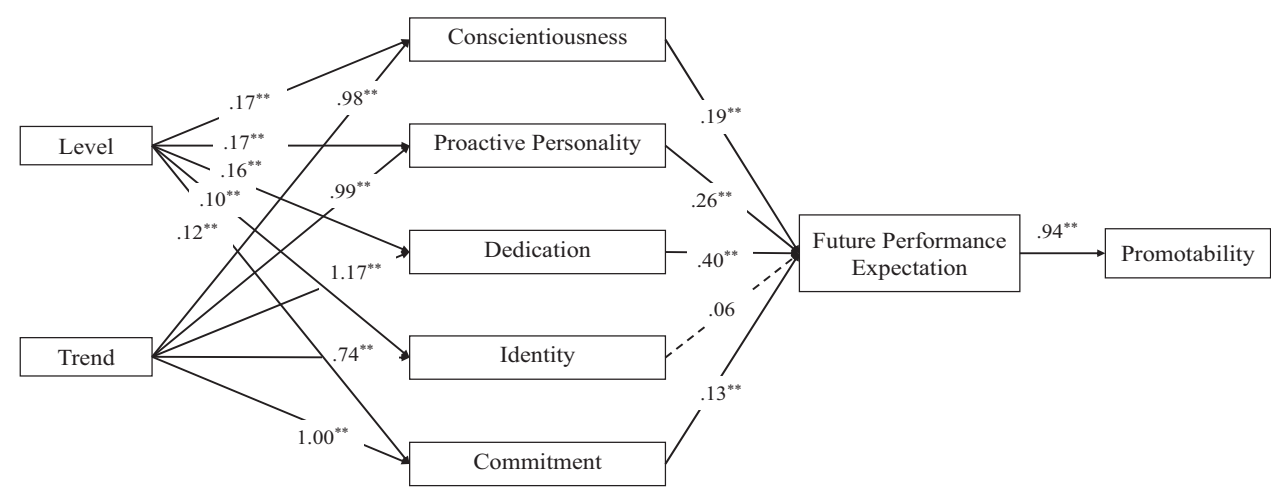

Figure 6. The path model (Study 3). All path coefficients are unstandardized. Dashed lines indicate nonsignificant paths. Trend: ascending performance trend coded as 2, descending performance trend coded as 1; Level: low level of end performance coded as 1 , high level of end performance coded as 2 . ${ }^{* *} p<.01$. 
Table 10

Descriptive Statistics, Cronbach's Alpha and Omega-h Values, and Intercorrelations for Study 4

\begin{tabular}{|c|c|c|c|c|c|c|c|c|c|c|}
\hline Variable & $M$ & $S D$ & 1 & 2 & 3 & 4 & 5 & 6 & 7 & 8 \\
\hline 1. Future performance & 3.84 & 0.73 & $(.84, .85)$ & & & & & & & \\
\hline 2. Promotability & 3.85 & 0.79 & $.78^{* *}$ & $(.85, .84)$ & & & & & & \\
\hline 3. Conscientiousness & 3.66 & 0.62 & $.33^{* *}$ & $.40^{* *}$ & $(.82, .72)$ & & & & & \\
\hline 4. Proactive personality & 3.85 & 0.73 & $.71^{* *}$ & $.79^{* * *}$ & $.37^{* * *}$ & $(.87, .86)$ & & & & \\
\hline 5. Dedication & 3.88 & 0.72 & $.71^{* *}$ & $.80^{* * *}$ & $.41^{* * *}$ & $.86^{* *}$ & $(.90, .90)$ & & & \\
\hline 6. Job identity & 3.63 & 0.90 & $.54^{* *}$ & $.57^{* *}$ & $.14^{* * *}$ & $.64^{* *}$ & $.67^{* *}$ & $(.82, .82)$ & & \\
\hline 7. Commitment & 3.76 & 0.77 & $.54^{* *}$ & $.61^{* *}$ & $.23^{* * *}$ & $.67^{* *}$ & $.68^{* *}$ & $.59^{* * *}$ & $(.76, .77)$ & \\
\hline 8. Person & 1.50 & 0.50 & $.44^{* *}$ & $.39^{* *}$ & $.12^{* * *}$ & $.40^{* *}$ & $.40^{* *}$ & $.27^{* * *}$ & $.19^{* *}$ & - \\
\hline
\end{tabular}

Note. Level $1 N=440$. All variables were within individual (Level 1) variables. Person: the target with a flat trend but high performance level was coded as 1, the target with an ascending trend but low performance level was coded as 2. Cronbach's alphas and McDonald's omega-hs are reported on the diagonal (averaged across the two stimuli).

*** $p<.01$.

level, then our advice would be to make decision makers aware of the tendency to attach importance to performance trend so that the right people are promoted. At present, however, it is not possible to know which advice to give.

\section{Limitations}

A possible limitation of our work is that our designs largely target the relationship between job performance trend and change in hierarchical level that one may observe for the average individual in our sample, be they a stellar, average, or low performer. Future studies may consider adopting an interrupted time series design to explore performance-promotion relationships from a more individual-centered perspective. In such studies, the possibility of a reciprocal relationship between job performance and promotions should be considered. It would be desirable to test the generalizability of our findings across different populations (e.g., outside of Europe) and in different organizations and cultural contexts. Also, it may be that relationships between performance change and changes in hierarchical level are weaker for jobs lower in complexity. Most of all, it seems important to replicate our results in specific phases of the work career, perhaps comparing entry-level workers to those with more experience. Moreover, it would be desirable (although not simple) in future studies to extend the temporal perspective, to increase the dynamicity of the model and to capture a larger proportion of a worker' job career.

An important point that emerged from this study is that longterm job performance and hierarchical level temporal trends are not necessarily linear and are sometimes subtle. Estimating such trends places a burden on researchers in that at least four time points and sufficiently large samples are necessary. A promising avenue for future studies would be to determine the optimal time lag within which the temporal trends of these variables unfold. In other words, for how long must a decision maker observe a trend to attach importance to it? Another interesting research avenue is to explore the convergence of manager's attributions of abilities and personality traits with subordinate's actual personality traits. These data could shed further light on the nature of the cognitive process leading to the promotion decision and the degree to which these processes are actually likely to result in promotion of the right people.

Related to this, Sturman (2007) pointed out that there are many learning curve models of performance trends. Although the Wright model (Yelle, 1979) is perhaps most common, Sturman (2007) lists several others. What these models share is the notion that performance trends are nonlinear. Beyond that, the models differ because of differing assumptions about the reasons for the trends. Future research should consider the possibility that trends con-

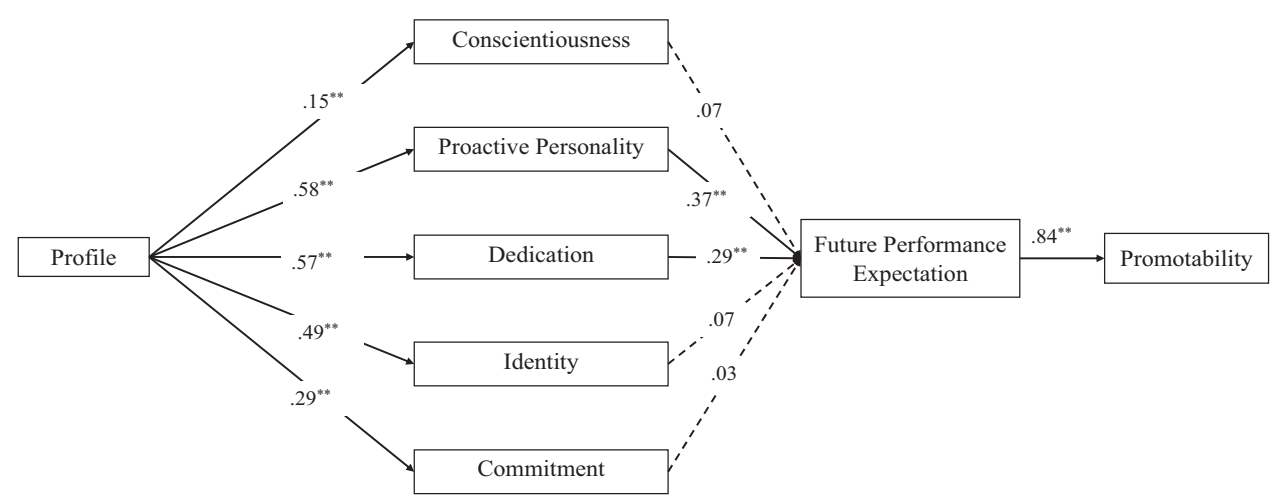

Figure 7. The path model (Study 4). All path coefficients are unstandardized. Dashed lines indicate nonsignificant paths. Profile: the target with a flat trend but high performance level was coded as 1 , the target with an ascending trend but low performance level was coded as 2 . ${ }^{* *} p<.01$. 
forming to different learning curve models have different meaning for decision makers. For example, it might be that the negative acceleration of the Wright model sends different signals to decision makers than does the S-shaped curve of the Sigmoid model (Carr, 1946). Alternatively, decision makers may have difficulty detecting the nuanced changes that exist in some of the more sophisticated models.

Another promising avenue for future research has to do with the relationship between performance trend in a lower-level job and actual performance in a subsequent, higher-level job. Our results show that decision makers are indeed inclined to promote those with upward performance trends. Future research should investigate the wisdom of this inclination. If, for example, future research showed that upward trends were unrelated, or even negatively related to performance in higher level jobs, the tendency to promote those with an upward trend should be seen as a bad habit to be broken through the same sort of training that is aimed at performance rating bias. Alternatively, although a gain in the knowledge needed to perform a lower level job may not, in itself, make one more likely to succeed in a higher level job, any stable attributes that led to that gain might be. If so, then the inclination to promote the person with the upward trend is justifiable.

Finally, despite their ubiquity, supervisor-based job performance ratings may exhibit different patterns over time than would more objective measures, and these different patterns might affect promotion decisions differently. Calls for research on job performance to focus on behavior rather than its outcomes notwithstanding (e.g., Sturman, 2007), it would be interesting to see whether the association between hierarchical levels and changes in job performance remain stable when objective indicators of job performance are used. Moreover, we note that the nature of the items comprising the job performance measure used in Study 1 puts a bound on the direct generalizability of our findings to other performance appraisal contexts.

The fact that the same PA system is used across hierarchical levels is a strength, relative to other performance-promotion studies, because it facilitates comparison of scores from one level to the next. Nevertheless, it does not ensure that the meaning and value of specific ratings (e.g., 4 on 5-point scale) are identical across levels. Given the differences in responsibilities, excellent performance may mean something quite different for Senior Manager AA than for junior specialist B. Perhaps the ideal organization for the study of performance-promotion relationships would be one in which all levels share some core set of job performance items, with level-specific responsibilities captured by items that are unique to a given level.

\section{Conclusion}

As can be seen from the results of the present study as well as the suggestions in the last few paragraphs, a dynamic perspective opens up new opportunities for those who wish to understand performance-promotion relationships. Based on our results, we offer a friendly amendment to the quote with which we began. "It matters where you came from and where you are, because that's AQ: 13 how I can tell where you are going."

\section{References}

Ackerman, P. L., Kanfer, R., \& Goff, M. (1995). Cognitive and noncognitive determinants and consequences of complex skill acquisition. Journal of Experimental Psychology: Applied, 1, 270. http://dx.doi.org/10 .1037/1076-898X.1.4.270

Alvares, K. M., \& Hulin, C. L. (1972). Two explanations of temporal changes in ability-skill relationships: A literature review and theoretical analysis. Human Factors, 14, 295-308. http://dx.doi.org/10.1177/ 001872087201400402

Ariely, D., \& Carmon, Z. (2003). Summary assessment of experiences: The whole is different from the sum of its parts. In G. Loewenstein, D. Read, \& R. Baumeister (Eds.), Time and decision: Economic and psychological perspectives on intertemporal choice (pp. 323-349). New York, NY: Russell Sage Foundation.

Ashkanasy, N. M. (1989). Causal attribution and supervisors' response to subordinate performance: The Green and Mitchell model revisited. Journal of Applied Social Psychology, 19, 309-330. http://dx.doi.org/10 .1111/j.1559-1816.1989.tb00057.x

Barnes, C. M., Reb, J., \& Ang, D. (2012). More than just the mean: Moving to a dynamic view of performance-based compensation. Journal of Applied Psychology, 97, 711-718. http://dx.doi.org/10.1037/a0026927

Bateman, T. S., \& Crant, J. M. (1993). The proactive component of organizational behavior: A measure and correlates. Journal of Organizational Behavior, 14, 103-118. http://dx.doi.org/10.1002/job 4030140202

Bentler, P. M., \& Chou, C. (1987). Practical issues in structural modeling. Sociological Methods \& Research, 16, 78-117. http://dx.doi.org/10 $.1177 / 0049124187016001004$

Blau, P. M. (1964). Exchange and power in social life. New York, NY: Wiley.

Bollen, K. A., \& Curran, P. J. (2006). Latent curve models. Hoboken, NJ: Wiley.

Breaugh, J. A. (2011). Modeling the managerial promotion process. Journal of Managerial Psychology, 26, 264-277. http://dx.doi.org/10.1108/ 02683941111124818

Burnham, K. P., \& Anderson, D. R. (2004). Multimodel inference: Understanding AIC and BIC in model selection. Sociological Methods \& Research, 33, 261-304. http://dx.doi.org/10.1177/0049124104268644

Carr, G. W. (1946, April). Peacetime cost estimating requires new learning curves. Aviation, 45, 76-77.

Chandler, J. J., \& Paolacci, G. (2017). Lie for a dime: When most prescreening responses are honest but most study participants are impostors. Social Psychological and Personality Science, 8, 500-508. http://dx.doi.org/10.1177/1948550617698203

Chen, F. F. (2007). Sensitivity of goodness of fit indexes to lack of measurement invariance. Structural Equation Modeling, 14, 464-504. http://dx.doi.org/10.1080/10705510701301834

Chen, G., Ployhart, R. E., Thomas, H. C., Anderson, N., \& Bliese, P. D. (2011). The power of momentum: A new model of dynamic relationships between job satisfaction change and turnover intentions. Academy of Management Journal, 54, 159-181. http://dx.doi.org/10.5465/amj .2011 .59215089

Cheong, J., Mackinnon, D. P., \& Khoo, S. T. (2003). Investigation of meditational process using parallel process latent growth curve modeling. Structural Equation Modeling, 10, 238-262. http://dx.doi.org/10 .1207/S15328007SEM1002_5

Cohen, J., Cohen, P., West, S. G., \& Aiken, L. S. (2003). Applied multiple regression/correlation analysis for the behavioral sciences (3rd ed.). Mahwah, NJ: Erlbaum.

Cortina, J. M., \& Luchman, J. N. (2013). Personnel selection and employee performance. In N. W. Schmitt, S. Highhouse, \& I. B. Weiner (Eds.), Industrial and organizational psychology (pp. 143-183). Hoboken, NJ: Wiley. 
Curran, P. J. (2003). Have multilevel models been structural equation models all along? Multivariate Behavioral Research, 38, 529-569. http://dx.doi.org/10.1207/s15327906mbr3804_5

Day, E. A., Arthur, W., \& Gettman, D. (2001). Knowledge structures and the acquisition of a complex skill. Journal of Applied Psychology, 86, 1022-1033. http://dx.doi.org/10.1037/0021-9010.86.5.1022

Deadrick, D. L., Bennett, N., \& Russell, C. J. (1997). Using hierarchical linear modeling to examine dynamic performance criteria over time. Journal of Management, 23, 745-757. http://dx.doi.org/10.1177/ 014920639702300603

DeNisi, A. S., Cafferty, T., \& Meglino, B. (1984). A cognitive view of the performance appraisal process: A model and research propositions. Organizational Behavior \& Human Performance, 33, 360-396. http:// dx.doi.org/10.1016/0030-5073(84)90029-1

DeNisi, A. S., \& Stevens, G. E. (1981). Profiles of performance, performance evaluations, and personnel decisions. Academy of Management Journal, 24, 592-602. http://dx.doi.org/10.2307/255577

Feldt, L. S., Woodruff, D. J., \& Salih, F. A. (1987). Statistical inference for coefficient alpha. Applied Psychological Measurement, 11, 93-103. http://dx.doi.org/10.1177/014662168701100107

Findley, H. M., Giles, W. F., \& Mossholder, K. W. (2000). Performance appraisal process and system facets: Relationship with contextual performance. Journal of Applied Psychology, 85, 634-640. http://dx.doi .org/10.1037/0021-9010.85.4.634

Green, S. G., \& Mitchell, T. R. (1979). Attributional processes of leaders in leader-member interactions. Organizational Behavior \& Human Performance, 23, 429-458. http://dx.doi.org/10.1016/0030-5073(79) 90008-4

Hansen, W. B., Tobler, N. S., \& Graham, J. W. (1990). Attrition in substance abuse prevention research: A meta analysis of 85 longitudinally followed cohorts. Evaluation Review, 14, 677-685. http://dx.doi .org/10.1177/0193841X9001400608

Harrison, D. A., Virick, M., \& William, S. (1996). Working without a net: Time, performance, and turnover under maximally contingent rewards. Journal of Applied Psychology, 81, 331-345. http://dx.doi.org/10.1037/ 0021-9010.81.4.331

Hausknecht, J. P., Sturman, M. C., \& Roberson, Q. M. (2011). Justice as a dynamic construct: Effects of individual trajectories on distal work outcomes. Journal of Applied Psychology, 96, 872-880. http://dx.doi .org/10.1037/a0022991

Heider, F. (1958). The psychology of interpersonal relations. New York, NY: Wiley. http://dx.doi.org/10.1037/10628-000

Henry, R. A., \& Hulin, C. L. (1987). Stability of skilled performance across time: Some generalizations and limitations on utilities. Journal of Applied Psychology, 72, 457-462. http://dx.doi.org/10.1037/0021-9010.72 .3 .457

Hsee, C. K., \& Abelson, R. P. (1991). Velocity relation: Satisfaction as a function of the first derivative of outcome over time. Journal of Personality and Social Psychology, 60, 341-347. http://dx.doi.org/10.1037/ 0022-3514.60.3.341

Hsee, C. K., Abelson, R. P., \& Salovey, P. (1991). The relative weighting of position and velocity in satisfaction. Psychological Science, 2, 263267. http://dx.doi.org/10.1111/j.1467-9280.1991.tb00146.x

John, O. P., Naumann, L. P., \& Soto, C. J. (2008). Paradigm shift to the integrative Big Five trait taxonomy: History, measurement, and conceptual issues. In O. P. John, R. W. Robins, \& L. A. Pervin (Eds.), Handbook of personality: Theory and research (pp. 114-158). New York, NY: Guilford Press.

Judge, T. A., Higgins, C. A., Thoresen, C. J., \& Barrick, M. R. (1999). The big five personality traits, general mental ability, and career success across the life span. Personnel Psychology, 52, 621-652. http://dx.doi .org/10.1111/j.1744-6570.1999.tb00174.x

Judge, T. A., Klinger, R. L., \& Simon, L. S. (2010). Time is on my side: Time, general mental ability, human capital, and extrinsic career suc- cess. Journal of Applied Psychology, 95, 92-107. http://dx.doi.org/10 1037/a0017594

Kahneman, D., \& Tversky, A. (1979). Prospect theory: An analysis of decision under risk. Econometrica, 47, 263-291. http://dx.doi.org/10 .2307/1914185

Kahneman, D., \& Tversky, A. (1984). Choices, values, and frames. American Psychologist, 39, 341-350. http://dx.doi.org/10.1037/0003-066X 39.4.341

Kanfer, R., \& Ackerman, P. L. (1989). Motivation and cognitive abilities: An integrative/aptitude-treatment interaction approach to skill acquisition. Journal of Applied Psychology, 74, 657-690. http://dx.doi.org/10 $.1037 / 0021-9010.74 .4 .657$

Kelley, H. H. (1967). Attribution theory in social psychology. In D. Levine (Ed.), Nebraska symposium on motivation (Vol. 15, pp. 192-238). Lincoln, NE: University of Nebraska Press.

Klein, A., \& Moosbrugger, H. (2000). Maximum likelihood estimation of latent interaction effects with the LMS method. Psychometrika, 65, 457-474. http://dx.doi.org/10.1007/BF02296338

Kline, R. B. (2016). Principles and practice of structural equation modeling. New York, NY: Guilford Press.

Lee, H., \& Dalal, R. S. (2011). The effects of performance extremities on ratings of dynamic performance. Human Performance, 24, 99-118. http://dx.doi.org/10.1080/08959285.2011.554467

Liden, R. C., Wayne, S. J., \& Stilwell, D. (1993). A longitudinal study on the early development of leader-member exchanges. Journal of Applied Psychology, 78, 662-674. http://dx.doi.org/10.1037/0021-9010.78.4 .662

Lindsley, D. H., Brass, D. J., \& Thomas, J. B. (1995). Efficacyperformance spirals: A multilevel perspective. The Academy of Management Review, 20, 645-678. http://dx.doi.org/10.2307/258790

Little, R. J. A., \& Rubin, D. B. (1987). Statistical analysis with missing data. New York, NY: Wiley.

Lombardo, M. M., \& Eichinger, R. W. (2000). High potentials as high learners. Human Resource Management, 39, 321-329. http://dx.doi.org/ AQ: 26 10.1002/1099-050X(200024)39:4<321::AID-HRM4>3.0.CO;2-1

Longenecker, K. O., \& Fink, L. S. (2008). Key criteria in twenty-first century management promotional decisions. The Career Development International, 13, 241-251. http://dx.doi.org/10.1108/13620430810870494

Lyness, K. S., \& Heilman, M. E. (2006). When fit is fundamental: Performance evaluations and promotions of upper-level female and male managers. Journal of Applied Psychology, 91, 777-785. http://dx.doi .org/10.1037/0021-9010.91.4.777

Maurer, T. J., \& Chapman, E. F. (2013). Ten years of career success in relation to individual and situational variables from the employee development literature. Journal of Vocational Behavior, 83, 450-465. http://dx.doi.org/10.1016/j.jvb.2013.07.002

Mayer, R. C., \& Davis, J. H. (1999). The effect of the performance appraisal system on trust for management: A field quasi-experiment. Journal of Applied Psychology, 84, 123-136. http://dx.doi.org/10.1037/ 0021-9010.84.1.123

McDonald, R. P. (1999). Test theory: A unified treatment. Mahwah, NJ: Erlbaum.

Meade, A. W., \& Craig, S. B. (2012). Identifying careless responses in survey data. Psychological Methods, 17, 437-455. http://dx.doi.org/10 1037/a0028085

Meyer, J. P., \& Allen, N. J. (1991). A three-component conceptualization of organizational commitment. Human Resource Management Review, 1, 61-89. http://dx.doi.org/10.1016/1053-4822(91)90011-Z

Meyer, J. P., Allen, N. J., \& Smith, C. (1993). Commitment to organizations and occupations: Extension and test of a three-component conceptualization. Journal of Applied Psychology, 78, 538-551. http://dx.doi .org/10.1037/0021-9010.78.4.538

Miller, C. C., Glick, W. H., \& Cardinal, L. B. (2005). The allocation of prestigious positions in organizational science: Accumulative advantage, 
sponsored mobility, and contest mobility. Journal of Organizational Behavior, 26, 489-516. http://dx.doi.org/10.1002/job.325

Mitchell, T. R., \& James, L. R. (2001). Building better theory: Time and the specification of when things happen. Academy of Management Review, 26, 530-547. http://dx.doi.org/10.5465/amr.2001.5393889

Murphy, K. R. (1989). Is the relationship between cognitive ability and job performance stable over time? Human Performance, 2, 183-200. http:// dx.doi.org/10.1207/s15327043hup0203_3

Muthén, B. O., \& Curran, P. J. (1997). General longitudinal modeling of individual differences in experimental designs: A latent variable framework for analysis and power estimation. Psychological Methods, 2, 371-402. http://dx.doi.org/10.1037/1082-989X.2.4.371

Muthén, L. K., \& Muthén, B. O. (1998-2018). Mplus user's guide. Los Angeles, CA: Muthén \& Muthén.

Necka, E. A., Cacioppo, S., Norman, G. J., \& Cacioppo, J. T. (2016). Measuring the prevalence of problematic respondent behaviors among MTurk, campus, and community participants. PLOS ONE, 11, e0157732. http://dx.doi.org/10.1371/journal.pone.0157732

Ng, T. W., Eby, L. T., Sorensen, K. L., \& Feldman, D. C. (2005). Predictors of objective and subjective career success: A meta-analysis. Personnel Psychology, 58, 367-408. http://dx.doi.org/10.1111/j.17446570.2005.00515.x

Ng, T. W. H., \& Feldman, D. C. (2008). The relationship of age to ten dimensions of job performance. Journal of Applied Psychology, 93, 392-423. http://dx.doi.org/10.1037/0021-9010.93.2.392

Ng, T. W. H., \& Feldman, D. C. (2010). Organizational tenure and job performance. Journal of Management, 36, 1220-1250. http://dx.doi.org/ 10.1177/0149206309359809

Noftle, E. E., \& Robins, R. W. (2007). Personality predictors of academic outcomes: Big five correlates of GPA and SAT scores. Journal of Personality and Social Psychology, 93, 116-130. http://dx.doi.org/10 $.1037 / 0022-3514.93 .1 .116$

Park, S., Sturman, M. C., Vanderpool, C., \& Chan, E. (2015). Only time will tell: The changing relationships between LMX, job performance, and justice. Journal of Applied Psychology, 100, 660-680. http://dx.doi .org/10.1037/a0038907

Parker, S. K. (1998). Enhancing role breadth self-efficacy: The roles of job enrichment and other organizational interventions. Journal of Applied Psychology, 83, 835-852. http://dx.doi.org/10.1037/0021-9010.83.6 .835

Pitariu, A. H., \& Ployhart, R. E. (2010). Explaining change: Theorizing and testing dynamic mediated longitudinal relationships. Journal of Management, 36, 405-429. http://dx.doi.org/10.1177/0149206308331096

Ployhart, R. E., \& Vandenberg, R. J. (2010). Longitudinal research: The theory, design, and analysis of change. Journal of Management, 36, 94-120. http://dx.doi.org/10.1177/0149206309352110

Powell, G. N., \& Butterfield, D. A. (1994). Investigating the "glass ceiling" phenomenon: An empirical study of actual promotions to top management. Academy of Management Journal, 37, 68-86. http://dx.doi.org/ $10.2307 / 256770$

Reb, J., \& Cropanzano, R. (2007). Evaluating dynamic performance: The influence of salient Gestalt characteristics on performance ratings. Journal of Applied Psychology, 92, 490-499. http://dx.doi.org/10.1037/ 0021-9010.92.2.490

Reb, J., \& Greguras, G. J. (2010). Understanding performance ratings: Dynamic performance, attributions, and rating purpose. Journal of Applied Psychology, 95, 213-220. http://dx.doi.org/10.1037/a0017237

Sackett, P. R., \& Lievens, F. (2008). Personnel selection. Annual Review of Psychology, 59, 419-450. http://dx.doi.org/10.1146/annurev.psych.59 .103006 .093716

Satorra, A., \& Bentler, P. M. (2001). A scaled difference chi-square test statistic for moment structure analysis Psychometrika, 66, 507-514. http://dx.doi.org/10.1007/BF02296192
Schmidt, F. L. (2002). The role of general cognitive ability and job performance: Why there cannot be a debate. Human Performance, 15, 187-210. http://dx.doi.org/10.1080/08959285.2002.9668091

Scott, W. E., Jr., \& Hamner, W. C. (1975). The influence of variations in performance profiles on the performance evaluation process: An examination of the validity of the criterion. Organizational Behavior \& Human Performance, 14, 360-370. http://dx.doi.org/10.1016/00305073(75)90036-7

Seibert, S. E., Crant, J. M., \& Kraimer, M. L. (1999). Proactive personality and career success. Journal of Applied Psychology, 84, 416-427. http:// dx.doi.org/10.1037/0021-9010.84.3.416

Selig, J. P., \& Preacher, K. J. (2008, June). Monte Carlo method for assessing mediation: An interactive tool for creating confidence intervals for indirect effects [Computer software].

Shore, L. M., \& Wayne, S. J. (1993). Commitment and employee behavior: Comparison of affective commitment and continuance commitment with perceived organizational support. Journal of Applied Psychology, 78, 774-780. http://dx.doi.org/10.1037/0021-9010.78.5.774

Stewart, G. L. (1999). Trait bandwidth and stages of job performance: Assessing differential effects for conscientiousness and its subtraits. Journal of Applied Psychology, 84, 959-968. http://dx.doi.org/10.1037/ 0021-9010.84.6.959

Stoolmiller, M. (1994). Antisocial behavior, delinquent peer association, and unsupervised wandering for boys: Growth and change from childhood to early adolescence. Multivariate Behavioral Research, 29, 263 288. http://dx.doi.org/10.1207/s15327906mbr2903_4

Sturman, M. C. (2007). The past, present, and future of dynamic performance research. In J. J. Martocchio (Ed.), Research in personnel and human resources management (Vol. 26, pp. 49-110). Bingley, UK: Emerald Group Publishing Limited.

Sturman, M. C., Hannon, J. M., \& Milkovich, G. T. (1996). Computerized decision aids for flexible benefits decisions: The effects of an expert system and decision support system on employee intentions and satisfaction with benefits. Personnel Psychology, 49, 883-908. http://dx.doi .org/10.1111/j.1744-6570.1996.tb02453.x

Sturman, M. C., \& Trevor, C. O. (2001). The implications of linking the dynamic performance and turnover literatures. Journal of Applied Psychology, 86, 684-696. http://dx.doi.org/10.1037/0021-9010.86.4.684

Thacker, R. A., \& Wayne, S. J. (1995). An examination of the relationship between upward influence tactics and assessments of promotability. Journal of Management, 21, 739-756. http://dx.doi.org/10.1177/ 014920639502100408

Thompson, L. (1998). The mind and heart of the negotiator. Upper Saddle River, NJ: Prentice Hall.

Thoresen, C. J., Bradley, J. C., Bliese, P. D., \& Thoresen, J. D. (2004). The big five personality traits and individual job performance growth trajectories in maintenance and transitional job stages. Journal of Applied Psychology, 89, 835-853. http://dx.doi.org/10.1037/0021-9010.89.5 .835

Turner, W. W. (1960). Dimensions of foreman performance: A factor analysis of criterion measures. Journal of Applied Psychology, 44, 216-223. http://dx.doi.org/10.1037/h0041010

Van Scotter, J. R., \& Motowidlo, S. J. (1996). Interpersonal facilitation and job dedication as separate facets of contextual performance. Journal of Applied Psychology, 81, 525-531. http://dx.doi.org/10.1037/0021-9010 .81 .5 .525

Van Scotter, J. R., Motowidlo, S. J., \& Cross, T. C. (2000). Effects of task performance and contextual performance on systemic rewards. Journal of Applied Psychology, 85, 526-535. http://dx.doi.org/10.1037/00219010.85.4.526

Von Neumann, J., \& Morgenstern, O. (1944). Theory of games and economic behavior. Princeton, NJ: Princeton University Press. 
Welbourne, T. M., \& Paterson, T. A. (2017). Advancing a richer view of identity at work: The role-based identity scale. Personnel Psychology, 70, 315-356. http://dx.doi.org/10.1111/peps.12150

West, S. G., Finch, J. F., \& Curran, P. J. (1995). Structural equation models with non-normal variables: Problems and remedies. In R. Hoyle (Ed.), Structural equation modeling: Concepts, issues, and applications (pp. 56-75). Thousand Oaks, CA: Sage.

Wexley, K. N., \& Klimoski, R. (1984). Performance appraisal an update. In K. M. Rowland \& G. R. Ferris (Eds.), Research in personnel and human resources management (Vol. 2, pp. 35-79). Greenwich, CT: JAI Press.

Yelle, L. E. (1979). The learning curve: Historical review and comprehensive survey. Decision Sciences, 10, 302-328. http://dx.doi.org/10.1111/ j.1540-5915.1979.tb00026.x
Yukl, G. (1994). Leadership in organizations (3rd ed.). Englewood Cliffs, NJ: Prentice Hall.

Zyphur, M. J., Bradley, J. C., Landis, R. S., \& Thoresen, C. J. (2008). The effects of cognitive ability and conscientiousness on performance over time: A censored latent growth model. Human Performance, 21, 1-27. http://dx.doi.org/10.1080/08959280701521967

Received June 28, 2019 Revision received May 8, 2020 Accepted May 8, 2020 